\title{
TREATMENT PROTOCOL FOR TEMPOROMANDIBULAR JOINT DERANGEMENT USING AN ANTERIOR REPOSITIONING SPLINT WITH MODIFICATION (ONE YEAR PROSPECTIVE STUDY)
}

\author{
Ehab A. Elsaih*, Bassant Mowafey ${ }^{* *}$, Fatma Ata ${ }^{* * *}$ and Ahmed S. Salem****
}

\begin{abstract}
Purpose: To study the patient with temporomandibular joint derangement concerning the subjective response and clinical outcome to a modified splint treatment protocol.

Materials and Methods: 12 patients were included with disc displacement with reduction (DDwR). The treatment protocol was initiated using an anterior repositioning splint (ARS) for 3 months and later completed with ARS modification into a stabilizing splint (SS) for the next 9 months. Follow-up was made over one year (6 weeks, 12 weeks, and 1-year intervals). The followup included the patient's self-evaluation, clinical examination, and MRI.
\end{abstract}

Results: In comparison to the base-line a significant improvement was recorded in the tested parameters; A) in 12 weeks follow up, the subjective data were; the pain frequency $(0.41 \pm 0.51)$, the pain degree $(0.25 \pm 0.45)$, the modified pain by chewing, movement, para-function, and other parameters were $0.08 \pm 0.28,0.25 \pm 0.45,0.25 \pm 0.45$, and $0.16 \pm 0.38$ respectively. B) in $6 \& 12$ weeks follow-ups the clinical parameters were; MCPS $0.58 \pm 0.51$, and $0.25 \pm 0.45$, the MYS $0.58 \pm 0.51$, $0.25 \pm 0.45$, the MD $1.91 \pm 0.66,0.58 \pm 0.51, \mathrm{C}$ ) the VAS scores, the mandibular movement range in the maximum opening, protrusive and both lateral directions, and the Helkimo's disability index scores were improved. In $3 \& 12$ months follow-ups the complete disc recapture diagnosed by MRI were $66 \%$ and $83 \%$ respectively.

Conclusion: There is a positive impact of the ARS on all criteria of patient subjective and clinical outcomes. The improvement continued after splint modification for the successive 9 months. Within the limitation of this study, and upon literature comparison, this treatment protocol is recommended in DDwR cases.

KEYWORDS : Anterior repositioning splint - temporomandibular disorders - disc derangement with reduction

\footnotetext{
* Associate professor of removable prosthodontics, Department of removable Prosthodontics, Faculty of Dentistry, Mansoura University.

** Associate professor of diagnosis and oral radiology, Oral medicine, periodontology, diagnosis and oral radiology department, Faculty of Dentistry, Mansoura University.

***Lecturer of diagnosis and oral radiology, Oral medicine, periodontology, diagnosis and oral radiology department, Faculty of Dentistry, Mansoura University.

***** Associate Professor of Oral and Maxillofacial Surgery, Faculty of Dentistry, Mansoura University.
} 


\section{INTRODUCTION}

The Mandible is connected to the skull through two bilateral synovial joints or temporomandibular joints (TMJ). The physiologic anatomy of these joints combined with the associated muscles and ligaments allows a multi-axis jaw movement necessary for various functional activities ${ }^{(1)}$.

Temporomandibular disorders (TMDs) is a famous orofacial pain (OFP), it refers to musculoskeletal disorders affecting the masticatory muscles, ligaments, and/or the TMJ components (disc, capsule, and/or osseous components) integrity and function (2,3). TMDs were described with multiple etiologic and/or perpetuating factors ${ }^{(4,5)}$.

TMDs' common presenting symptom is pain (injoint and pre-joint area), which is usually triggered by emotions, stress ${ }^{(6)}$, and it is aggravated by chewing or other jaw muscle activities ${ }^{(7)}$. Thus it can limit, modify, interfere or hinder the normal jaw physiologic functions ${ }^{(8)}$.

Depending on the onset, not the severity, the pain is either acute or chronic, the main categories of chronic type are; a) somatic (dull, achy pain in soft or hard tissues), b) neurogenic (burning or stabbing neuropathic / nerve damage pain), and c) Psychogenic (emotional/ mood-related and lacks organic origins) ${ }^{(9,10,11)}$. A patient may present a combination of two of these categories or even all combined ${ }^{(12)}$.

Ongoing orofacial pain (OFP) for more than three months was considered chronic ${ }^{(13)}$.

TMDs etiology may be; a) muscle disorders (myalgia ${ }^{(14)}$ or nonspecific pain of masticatory muscles), b) disc displacement (DD) with reduction (DDwR), or without reduction (DDwoR) ${ }^{(15)}$. the DD may be accompanied or not by locking in opening or closure ${ }^{(16)}$. DD is also termed in literature "internal derangement" which refers to "a peripheral separation of the disc from its capsular, ligamentous, or osseous attachments"
${ }^{(17)}$, c) degenerative joint disease (DJD), it includes osteoarthrosis, osteoarthritis, capsulitis, synovitis, and degenerative articular disc thinning or even perforation ${ }^{(\mathbf{1 8 , 1 9 )}}$.

Occlusion-related problems was claimed related or etiologic to TMD (21, 22, 23, 24, 25,26). But this cause-effect relation was long considered a field of controversy ${ }^{(27)}$. nevertheless, the lack of consistency even among those studies that support such assumption ${ }^{(28)}$. And it was reported as a consequence rather than the origin ${ }^{(29)}$.

MRI findings coupled with careful interdisciplinary diagnosis may point out the TMD type ${ }^{(30)}$. The TMD with DD, especially DDwR, may include a myalgia (2ry myalgia) ${ }^{(31)}$, occlusal deviation (32,33), facial asymmetry (displacement asymmetry) ${ }^{(34)}$, a TMJ site pain component ${ }^{(35)}$, clicking or crepitus ${ }^{(15)}$, or a combination of these symptoms.

The TMD non-surgical approach consists of a recognized health care protocol set that includes; a) cognitive-behavioral therapy aiming for relaxation and habit-breaking ${ }^{(36,37)}$, b) pharmacological approach (using Anti-inflammatories and muscle relaxants or anti-depressants in severe cases) ${ }^{(38,39)}$, c) modalities of physical therapy (electro-physical, massage, or physical exercise) ${ }^{(\mathbf{4 0 , 4 1 )}, d) ~ W e a r i n g ~ a n ~}$ oral appliance (OAs) or an occlusal orthotic (splint) ${ }^{(42)}$, e) a combination of these approaches.

The occlusal splint therapy is a common worldwide accepted TMDs management ${ }^{(43)}$. The commonly used types in DD cases are ${ }^{(44,45,46)} ; 1$ ) stabilization splints, which are used in the treatment of nocturnal bruxism, and usually covers all teeth and prescribed to be worn at night to prevent clenching and grinding of teeth, 2) repositioning splints, which are used to alter the occlusal relation and mandibular relation as the anterior repositioning splint (ARS), it fits on the teeth occlusal surface (maxillary or mandibular), and these splints are typically instructed for a day and night use and 
usually prescribed al for a short period (not to exceed 3 - 4 months or up to 6 months).

Efficacy of oral appliances used in DD management was hypothetically related to $\left.{ }^{(47,48,49)} ; 1\right)$ dental causes as, a) altering the occlusal relation, b) altering the condylar relation, c) controlled increase in the vertical dimension. 2) non-dental causes, a) altering the cognitive awareness, b) decreasing the related muscles' motor activity, c) placebo effect.

If the short-term use of ARS (2-3months) was combined with relatively long-term use of stabilizing splint, the benefits of both may offer better effect and clinical results. Thus this study aimed to test the null hypothesis that the modified ARS into a stabilization splint will offer a good patient outcome and clinical response in cases of TMD that demonstrates DDwR especially in cases with radiographic signs of moderate disc changes.

\section{MATERIAL AND METHODS}

This work was processed and approved according to ethical guidelines of the academic ethics committee, college of dentistry, Mansoura University (A12051021), then each patient was informed about the treatment plan and followup regime and asked to sign informed consent according to the college regulations before the clinical procedures.

\section{Patient selection}

From the subjects diagnosed with OFP (50), twelve patients were selected according to Kuc et al (51) controlled inclusion and exclusion criteria. The selected cases were diagnosed as TMD, internal derangement patients (anterior disc displacement with reduction), in addition to MRI reported unilateral moderate degenerative changes and mediolateral deviation upon opening (detailed in next section). The patients' pre-treatment life table (baseline data) was presented in table 1 .

\section{pre-treatment radiographic examination}

Pre-treatment cone-beam computed tomography (CBCT) was made to disclose any osseous morphology and pathology ${ }^{(52,53)}$ (figure 1a,b).

Pre-treatment sagittal MRI imaging (figure 1a,b,c) were made in; 1) closed mouth (maximum intercuspation), and in 2) open mouth where the patients maintained in maximum opening that was assessed as follows; open-mouth MRI images was more than $(10-15 \mathrm{~mm}$ measured at an inter-incisal distance) and reach the maximum opening without pain beyond the last opening click (approximately 40-45mm measured at an inter-incisal distance).

TABLE (1) Pre-treatment life table (base line data) of the study subjects based on preliminary diagnosis and MRI reports.

\begin{tabular}{cccccccccccccc}
\hline Cases & 1 & 2 & 3 & 4 & 5 & 6 & 7 & 8 & 9 & 10 & 11 & 12 & N=12 \\
\hline Gender (M/F) & F & F & F & F & F & F & F & F & M & M & M & M & $1: 2$ \\
\hline Age (Years) & 33 & 33 & 34 & 42 & 36 & 39 & 38 & 37 & 43 & 46 & 49 & 47 & $39.7 \pm 5.5(49 / 33 / 16)$ \\
PD (Month/s) & 7 & 9 & 7 & 6 & 13 & 11 & 9 & 8 & 7 & 8 & 11 & 12 & $9 \pm 2.2(6 / 13 / 7)$ \\
\hline & & & & & & & & & & & & & Mode $/$ Median $(\mathbf{M a x} / \mathbf{M i n} / \mathbf{R})$ \\
\hline MRI Contra DT & 2 & 3 & 2 & 1 & 1 & 2 & 3 & 2 & 2 & 2 & 2 & 1 & $2 / 2(3 / 1 / 2)$ \\
MRI Ipsi DT & 1 & 0 & 0 & 0 & 1 & 0 & 1 & 1 & 0 & 1 & 0 & 0 & $1 / .5(1 / 0 / 1)$
\end{tabular}

$P D=$ Pain Duration in months Contra $=$ Contralateral, Ipsi= Ipsilateral, DT $=$ disc thickness, $($ normal $=0$, moderate $=1$, thin $=2$, very thin=3, perforated $=4$ ), Mean $=X$, Standard deviation $=S D$, Maximum $=$ Max, Minimum $=$ Min, Range $=R$ 
The patient's predetermined vertical jaw separation was maintained upon biting on a stack of tongue blades at open mouth scans ${ }^{(54)}$.

The DD was present when the disc posterior band (PB) was located within the articular eminence inferior part, and the DD was partially present when PD was located within the articular eminence middle part, and the DD was considered recaptured when disc PB was located within the articular eminence superior part ${ }^{(55,56)}$.

\section{pre-treatment (self-evaluation \& clinical assessment)}

Patient self-evaluation was carried out through "Form 1". This form is a translated, modified short screening instrument from Gonzalez et al (57). The self-report questionnaires address the pain frequency and degree as well as pain modification by chewing movement, para-function or others ${ }^{(58)}$.

Tow examiners used "Form 2", that was designed according to TMD research diagnostic criteria (RDC/ TMD) ${ }^{(58)}$, the form consists of 3 parts as follows; A) first part help to assess pain and disability in terms of a Modified Chronic Pain Disability Scale (MCPS) in which $(0=$ no pain $\&$ no disability, $1=$ low pain \& no/ low disability, $2=$ moderate pain \& no/ low disability, $3=$ moderate pain $\&$ low $/$ moderate disability, $4=$ high intensity pain $\&$ high disability or even severely limiting situation) ${ }^{(57)}$, B) second part helps to assess secondary myalgia in terms of a pain site scale (MYS), in which $(0=$ no pain, $1=$ local pain at palpation site, $2=$ pain spreading beyond palpation site within the palpated muscle, $3=$ pain spreading beyond palpation site and beyond the palpated muscle) ${ }^{(59)}, \mathrm{C}$ ) third part is used to assess the opening deviation from mid line (OD) or the mediolateral shift that deviates the mandibular closing path, the measurements indicated the deviation of the lower incisors midline in relation to upper incisors mid line from maximum intercuspation and maximum opening.. The difference in millimeters were recorded in terms of ( $0=$ no shift, $1=1-2 \mathrm{~mm}$, $2=3-4 \mathrm{~mm}, 3=5 \mathrm{~mm}, 4=$ more than $5 \mathrm{~mm})^{(60,61)}$.
The selected subjects were assessed by different methods as follows;

\section{1) VAS scores}

VAS is a visual analog scale score, where 10 -centimeter horizontal scale scores were used to denote pain level from patient prospect $(0=$ minimum and $10=$ maximum $)^{(62,63)}$.

\section{2) Mandibular movement assessment}

Mandibular movement assessment to extract the mean of three successive measurements using digital caliper for each item of them: a) MMO (maximum mouth opening without pain measured in millimeters between upper and lower central incisors or corresponding level), b) FMO (Dentist controlled maximum mouth opening beyond painful limitation, using thumb moderate pressure on lower incisors while index finger resting on upper incisors, measured in millimeters between upper and lower central incisors or corresponding level), c) lateral movement in relation to affected joint disc based on MRI data were measured as ILE (Ipsi-lateral excursion) and CLE (Contra-lateral excursion), measurements were in millimeters between upper and lower incisors midline by asking the subject to move the slightly opened mouth in maximum non painful lateral direction starting by the affected "ipsilateral" side, d) PE or protrusive excursion, denoting the maximum horizontal distance measurements in millimeters between upper and lower incisal edges from maximum intercuspation till maximum protrusion ${ }^{(64-66)}$.

\section{3) Helkimo index (dysfunction index or Di) ${ }^{(67,68)}$.}

This index the anamnestic function throw grading or symptomatic evaluation for dysfunction at baseline (pre-treatment) and after treatment (posttreatment). The index addresses 5 signs which are; 1 ) range of jaw movement, 2) smooth movement with no deviation or sounds, 3) movement pain, 4) joint pain, 5) jaw muscles pain. The index scores (Di0, 


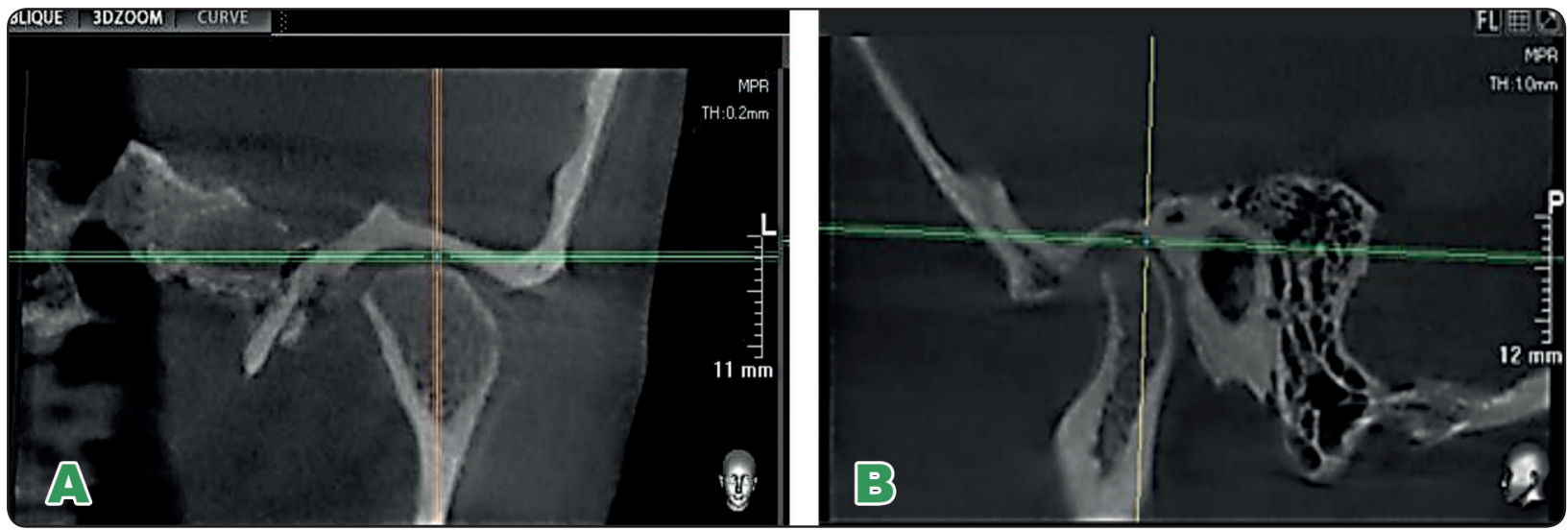

Fig. (1) CBCT of the affected joint side showing a normal joint space and bone integrity in condyle head and fossa, a) coronal view, b) sagittal view.

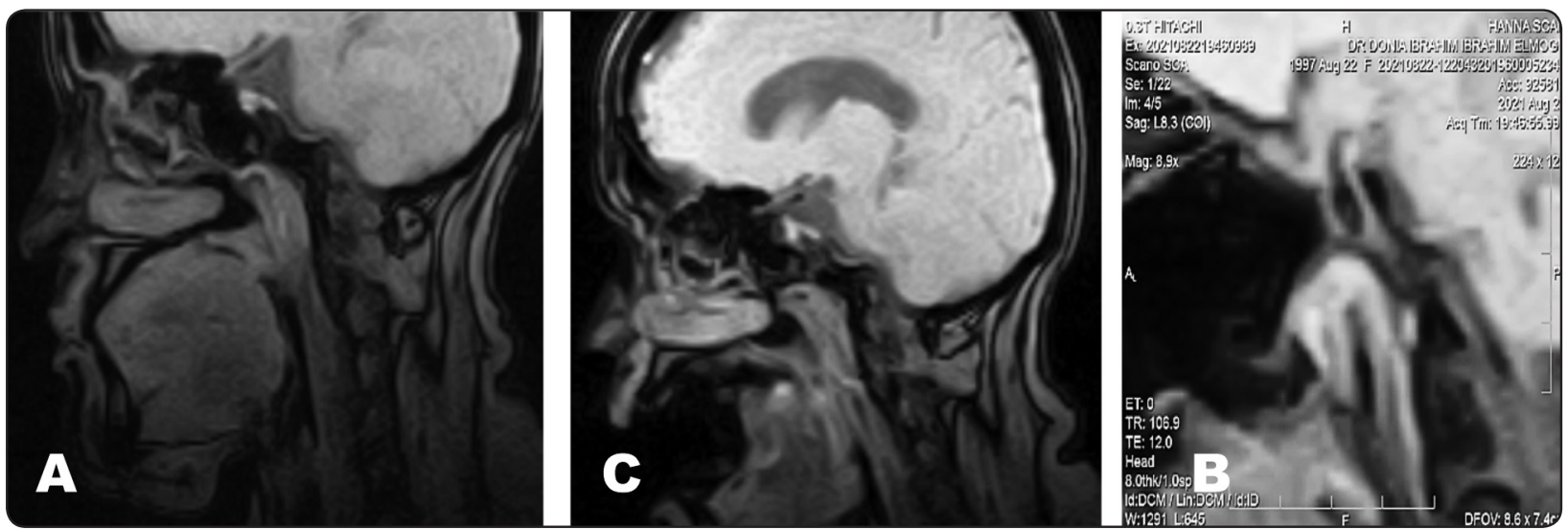

Fig. (2) MRI of the affected joint side in sagittal section, a) closed mouth, b) open mouth, c) anterior disc displacement with no signs of recapture.

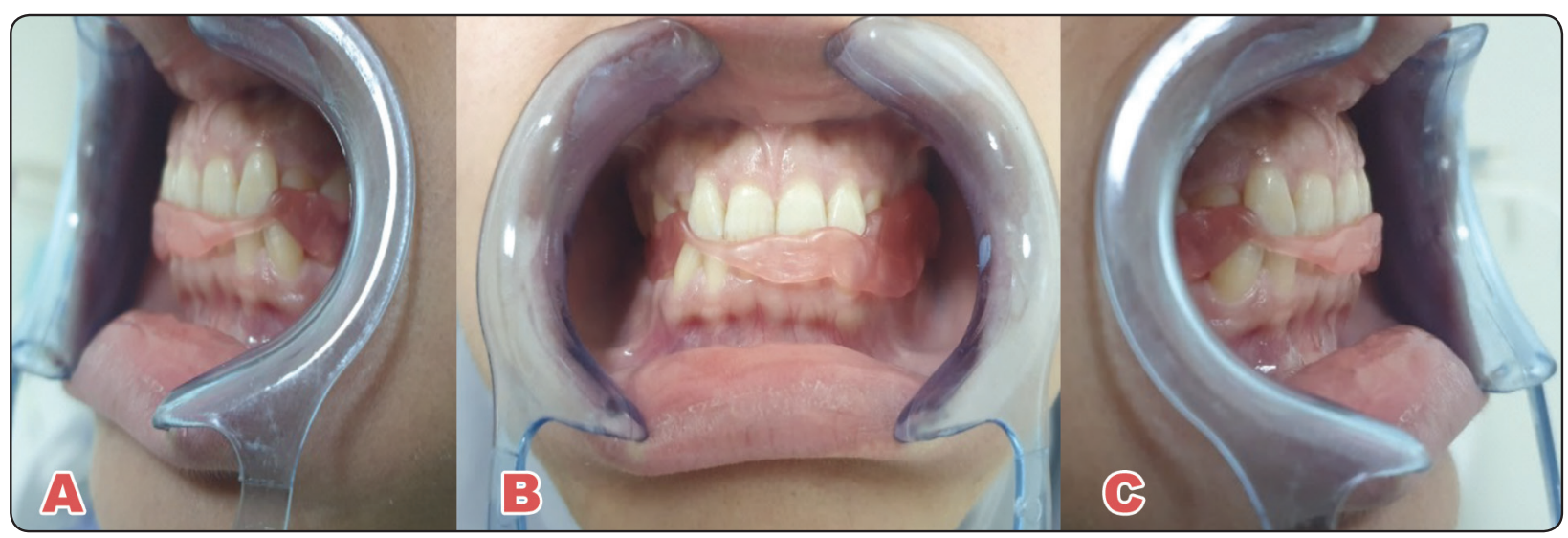

Fig. (3) centric wax inter-occlusal record; a) right side, b) frontal view, c) right view. 


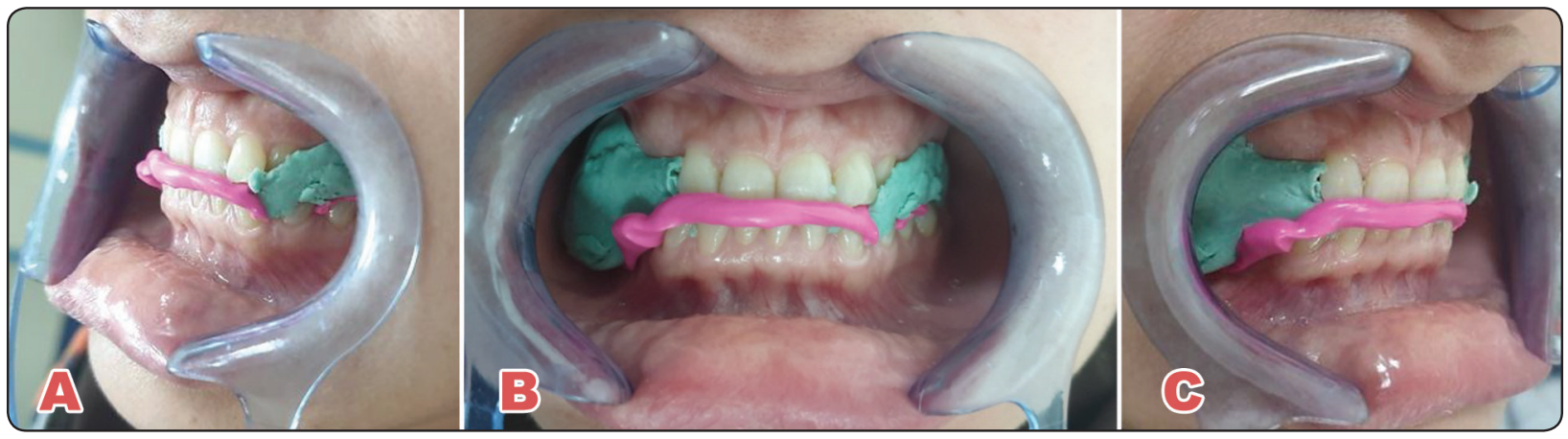

Fig. (4) protrusive rubber base occlusal record; a) right side, b) frontal view, c) right view.

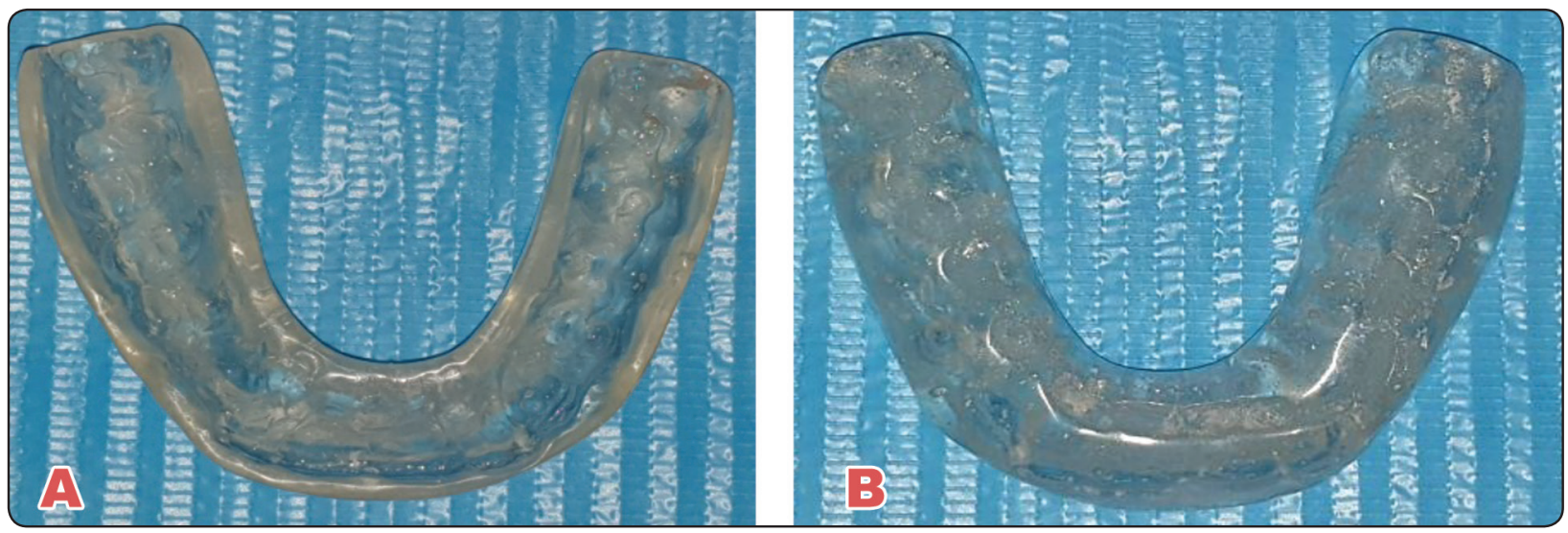

Fig. (5) clear acrylic maxillary A-P splint a) right side, b) frontal view, c) right view.
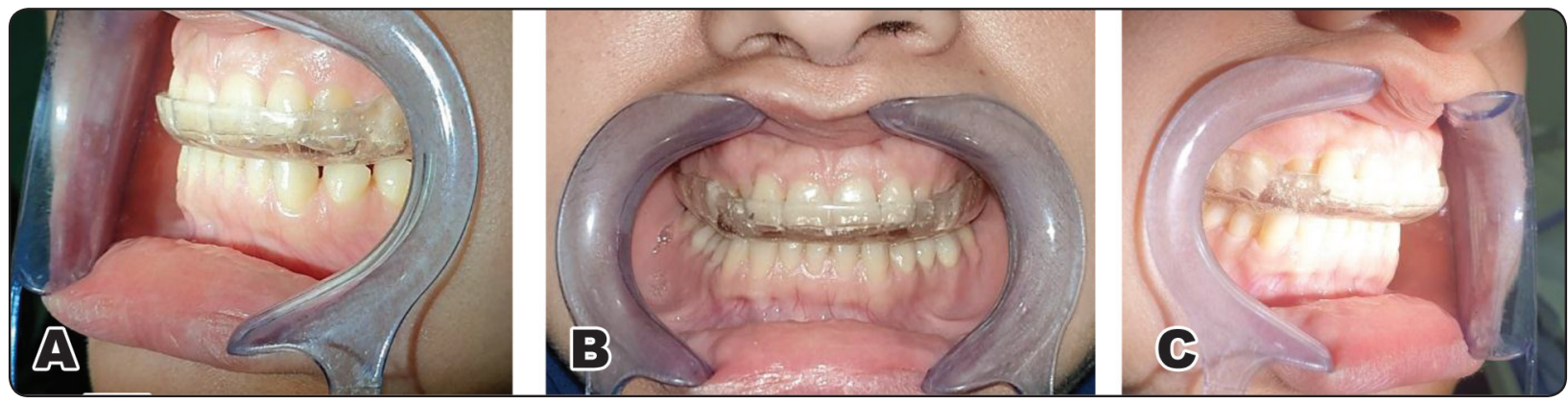

Fig. (6) clear acrylic maxillary A-P splint; a) intaglio surface, b) polished surface with indentation for mandibular anterior teeth.

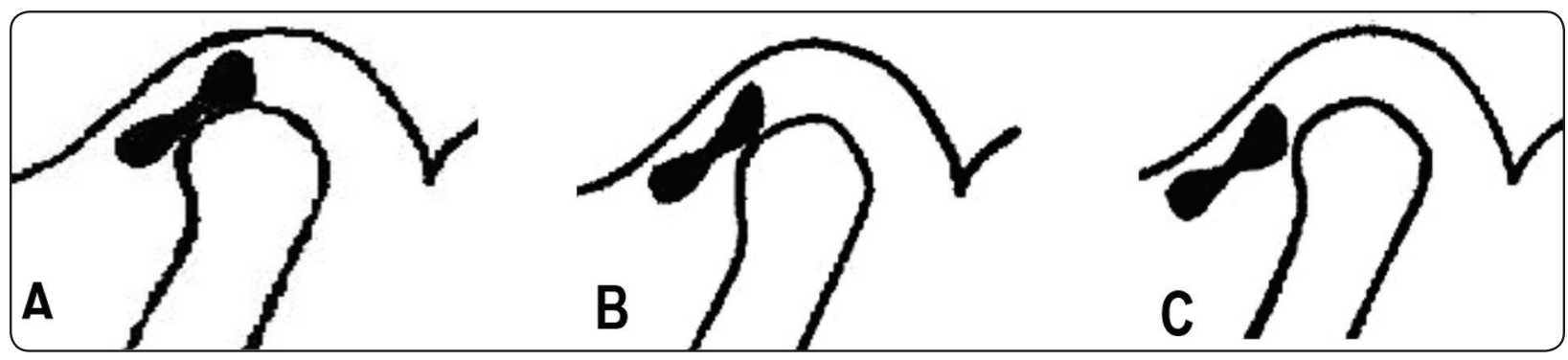

Fig. (7) Diagrammatic presentation for the status of disc-condyle relationship, a) complete recapture, b) partial recapture, c) no recapture. 
Di1, Di2, Di3) were as follows; a) 0 points score refers to Di0 or "No symptoms", b) 1-4 points score refers to Di1 or "Mild symptoms", c) 5-9 points score refers to Di2 or "Moderate symptoms", d) $>9$ points score refers to Di3 or "Sever symptoms".

\section{ARS construction and modification protocol}

Maxillary and mandibular impressions were made and poured to produce working models. For each patient, the following records were made: 1) Guided centric, rubber base, 2-3mm thickness, wax

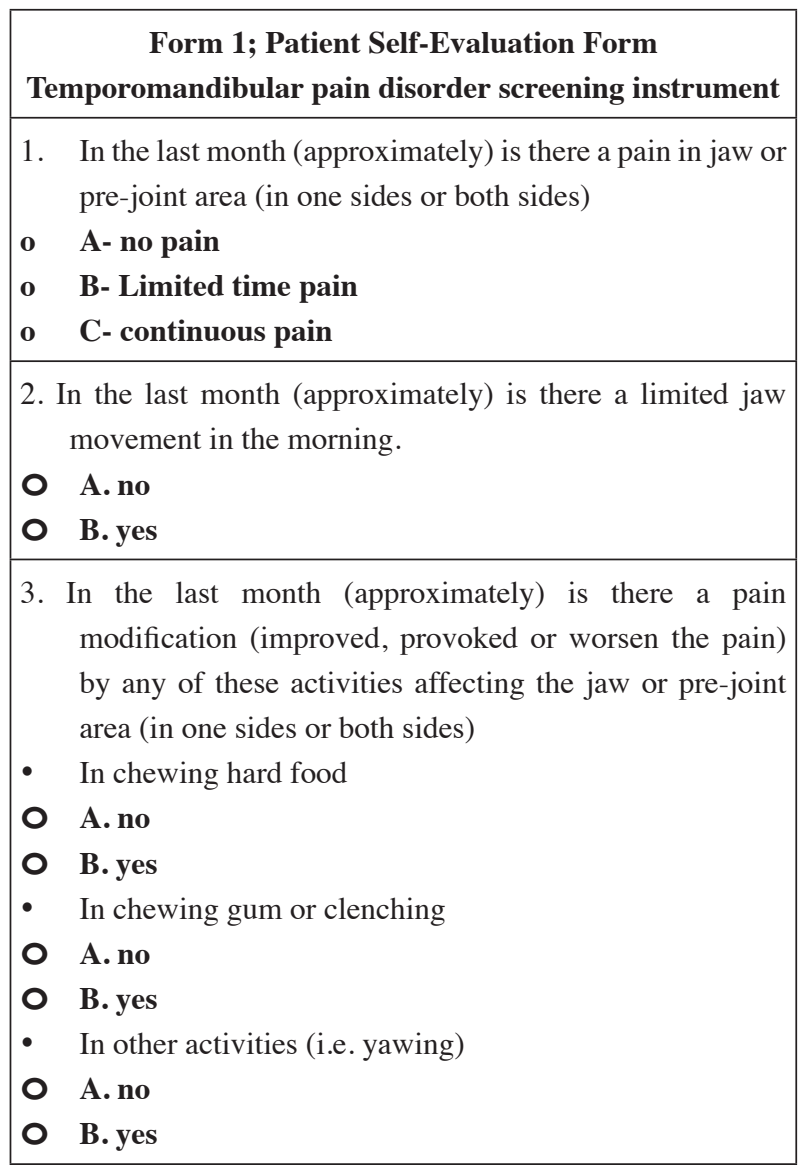

Modified Short screening instrument with 3 questions ( $A=$ $0, B=1, C=2$ )

The used version was translated and edited from (Gonzalez YM, Schiffman E, Gordon SM, Seago B, Truelove EL, Slade G, Ohrbach R. Development of a brief and effective temporomandibular disorder pain screening questionnaire: reliability and validity. J Am Dent Assoc. 2011 Oct;142(10):1183-91.) inter-occlusal record (figure 3a,b,c). 2) controlled protrusive, edge to edge, rubber base record (figure $4 a, b, c)(4-6 \mathrm{~mm}$ anterior to centric occlusal position) ${ }^{(69)}$.

In both records, the maxillary and mandibular midline were assured to superimpose each other. Records were used for semi-adjustable articulator mounting and programming. Clear acrylic maxillary anterior repositioning splint was waxed, processed, finished \& polished with 3-4mm thickness (or slightly more) at the thinnest portion (figure 5a).

Form 2; Diagnostic Pain/ Disability/ Occlusion assessment Temporomandibular pain disorder screening instrument

A- Modified Chronic Pain/ disability Scale

0- No pain, No disability

1- low pain, $\mathrm{No} /$ low disability

2- Moderate pain, No/ low disability

3- Moderate pain, low/ moderate disability

4- High intensity pain, high disability, severely limiting

2- Secondary Myalgia Scale

0 - No pain

1- local pain at palpation site

2- pain spreading beyond palpation

3- $\quad$ site within the palpated muscle

4- pain spreading beyond palpated muscle \& palpation site

3- Med-line deviation in maximum opening
0 - no deviation
1 - $1 \mathrm{~mm}$
2- $2 \mathrm{~mm}$
3- $3 \mathrm{~mm}$
4- $4 \mathrm{~mm}$

MCPS = Modified Chronic Pain Disability Scale, $(0=$ No pain, No disability, 1= low pain, No/ low disability, 2= Moderate pain, No/ low disability, 3= Moderate pain, low/ moderate disability, 4= High intensity pain, high disability, severely limiting)

MYS = secondary myalgia pain/extension scale, $(0=$ no pain, $1=$ local pain at palpation site, $2=$ pain spreading beyond palpation site within the palpated muscle, $3=$ pain spreading beyond palpation site and beyond the palpated muscle)

$\mathrm{MD}=$ Mid-line deviation in maximum intercuspation $(0=$ no shift, $1=1 \mathrm{~mm}, 2=2 \mathrm{~mm}, 3=3 \mathrm{~mm}, 4=4 \mathrm{~mm}$ ). 
Teeth indentations were faint posteriorly (indefinite occlusal stop) or nearly flat, while definite indentation (stops) for the lower incisors (figure $5 b)^{(70,71)}$.

Major occlusal interferences were checked first then the finished ARS was delivered (figure 6a,b,c). occlusal contacts were checked at least 2 times in the next 2 weeks. Patients were instructed for day and night use ${ }^{(72)}$ and to comply with scheduled follow-up.

After 3 months of use the splint was converted to a stabilization splint through; preserving 2-3mm thickness for posterior disclosure, creation of posterior simultaneous contacts and canine guidance anterior contact, and the removal of anterior indentation. The patient was instructed to continue use during the night and for one year ${ }^{(73)}$. Form 1,2, and examination procedures were used to collect data presented in tables 2, 3, and 4 .

\section{Post-treatment radiographic examination}

After 3 months and 1 year periods, a post-treatment MRI was made for all cases in closed moth (maximum intercuspation) to disclose the presence or absence of "disc recapture" (figure 7a,b,c). Comparison with pre-treatment MRI was done by the same examiner to disclose the disc recapture sequence achievement ${ }^{(54-56)}$.

\section{Statistical analysis}

Descriptive and inferential statistics were calculated using IBM ${ }^{\circledR}$ SPSS $® 2$ 25. Repeatedmeasures ANOVA is used at significance level $\mathrm{P} \leq$ 0.05 , to compare changes in the same group with the same variables in successive periods of the study.

TABLE (2) 12 weeks pre-/post-treatment subjective data based on the output of "Patient self-evaluation Form 1".

\begin{tabular}{|c|c|c|c|c|c|c|c|c|c|c|c|c|c|c|c|c|c|}
\hline \multirow{2}{*}{ Categories } & \multirow{2}{*}{ Item } & \multirow{2}{*}{ Period } & \multicolumn{12}{|c|}{ Cases } & \multicolumn{3}{|c|}{ Statistics } \\
\hline & & & 1 & 2 & 3 & 4 & 5 & 6 & 7 & 8 & 9 & 10 & 11 & 12 & $\mathrm{X} \pm \mathrm{SD}$ & $C V$ & $\mathrm{P}$ \\
\hline \multirow{4}{*}{$\begin{array}{c}\text { Pain \& } \\
\text { discomfort }\end{array}$} & \multirow{2}{*}{ Frequency } & pre & 2 & 2 & 3 & 1 & 1 & 1 & 2 & 1 & 1 & 1 & 2 & 2 & $1.58 \pm 0.66$ & 0.42 & \multirow{2}{*}{$P^{*}$} \\
\hline & & post & 1 & 1 & 1 & 0 & 0 & 1 & 1 & 0 & 0 & 0 & 0 & 0 & $0.41 \pm 0.51$ & 1.23 & \\
\hline & \multirow{2}{*}{ Degree } & pre & 2 & 2 & 2 & 1 & 1 & 0 & 1 & 1 & 0 & 0 & 1 & 1 & $1.00 \pm 0.73$ & 0.73 & \multirow{2}{*}{$P^{*}$} \\
\hline & & post & 1 & 1 & 1 & 0 & 0 & 0 & 0 & 0 & 0 & 0 & 0 & 0 & $0.25 \pm 0.45$ & 1.80 & \\
\hline \multirow{8}{*}{ 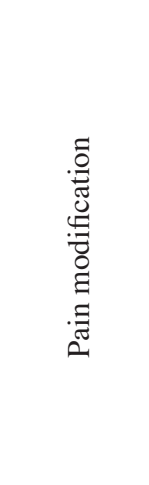 } & \multirow{2}{*}{ Chewing } & pre & 0 & 0 & 1 & 0 & 1 & 1 & 1 & 1 & 1 & 0 & 0 & 1 & $0.58 \pm 0.51$ & 0.88 & \multirow{2}{*}{$P^{*}$} \\
\hline & & post & 0 & 0 & 0 & 0 & 0 & 0 & 1 & 0 & 0 & 0 & 0 & 0 & $0.08 \pm 0.28$ & 3.46 & \\
\hline & \multirow{2}{*}{ Movement } & pre & 1 & 1 & 1 & 0 & 0 & 0 & 1 & 0 & 0 & 1 & 1 & 0 & $0.50 \pm 0.52$ & 1.04 & \multirow{2}{*}{$P^{*}$} \\
\hline & & post & 1 & 0 & 1 & 0 & 0 & 0 & 0 & 0 & 0 & 0 & 1 & 0 & $0.25 \pm 0.45$ & 1.80 & \\
\hline & \multirow{2}{*}{$\begin{array}{l}\text { Para- } \\
\text { function }\end{array}$} & pre & 1 & 1 & 1 & 0 & 1 & 1 & 1 & 0 & 0 & 1 & 1 & 1 & $0.75 \pm 0.45$ & 0.60 & \multirow{2}{*}{$P^{*}$} \\
\hline & & post & 1 & 0 & 1 & 0 & 0 & 0 & 0 & 0 & 0 & 0 & 0 & 1 & $0.25 \pm 0.45$ & 1.80 & \\
\hline & \multirow{2}{*}{ Others } & pre & 1 & 1 & 0 & 0 & 1 & 1 & 1 & 1 & 1 & 1 & 1 & 1 & $0.83 \pm 0.38$ & 0.46 & \multirow{2}{*}{$P^{*}$} \\
\hline & & post & 0 & 1 & 0 & 0 & 0 & 1 & 0 & 0 & 0 & 0 & 0 & 0 & $0.16 \pm 0.38$ & 2.33 & \\
\hline
\end{tabular}

Mean $=X$, Standard deviation $=S D, P=$ comparison with pre-treatment status, $P^{*}=$ statistically significant difference when value is $(<0.001)$ 
TABLE (3) 6 weeks and 12 weeks pre-/post-treatment subjective data based on the output of " Clinical Examination Form 2".

\begin{tabular}{|c|c|c|c|c|c|c|c|c|c|c|c|c|c|c|c|c|}
\hline \multirow{2}{*}{ Categories } & \multirow{2}{*}{ Periods } & \multicolumn{12}{|c|}{ Cases } & \multicolumn{3}{|c|}{ Statistics } \\
\hline & & 1 & 2 & 3 & 4 & 5 & 6 & 7 & 8 & 9 & 10 & 11 & 12 & $X \pm S D$ & $C V$ & $\mathrm{P}$ \\
\hline \multirow{3}{*}{ MCPS } & pre & 2 & 3 & 2 & 1 & 1 & 2 & 3 & 2 & 2 & 2 & 2 & 1 & $1.91 \pm 0.66$ & 0.34 & \\
\hline & Post (6w) & 1 & 1 & 1 & 1 & 0 & 1 & 0 & 1 & 0 & 1 & 0 & 0 & $0.58 \pm 0.51$ & 0.88 & $P^{*}$ \\
\hline & Post(12w) & 0 & 1 & 0 & 0 & 0 & 0 & 1 & 0 & 0 & 1 & 0 & 0 & $0.25 \pm 0.45$ & 1.80 & $P^{*}$ \\
\hline \multirow{3}{*}{ MYS } & pre & 1 & 2 & 1 & 0 & 1 & 1 & 2 & 2 & 2 & 2 & 1 & 1 & $1.33 \pm 0.65$ & 0.48 & \\
\hline & Post (6w) & 1 & 1 & 1 & 0 & 0 & 0 & 1 & 1 & 1 & 1 & 0 & 0 & $0.58 \pm 0.51$ & 0.88 & $P^{*}$ \\
\hline & Post(12w) & 1 & 1 & 1 & 0 & 0 & 0 & 0 & 0 & 0 & 0 & 0 & 0 & $0.25 \pm 0.45$ & 1.80 & $P^{*}$ \\
\hline \multirow{3}{*}{$\mathrm{MD}$} & pre & 3 & 4 & 4 & 3 & 3 & 3 & 3 & 3 & 3 & 3 & 3 & 2 & $3.08 \pm 0.51$ & 0.16 & \\
\hline & Post (6w) & 2 & 3 & 2 & 1 & 1 & 2 & 3 & 2 & 2 & 2 & 2 & 1 & $1.91 \pm 0.66$ & 0.34 & $P^{*}$ \\
\hline & Post(12w) & 1 & 1 & 1 & 1 & 1 & 1 & 1 & 0 & 0 & 0 & 0 & 0 & $0.58 \pm 0.51$ & 0.88 & $P^{*}$ \\
\hline
\end{tabular}

MCPS = Modified Chronic Pain Disability Scale, $(0=$ No pain, No disability, $1=$ low pain, No/low disability, $2=$ Moderate pain, No/ low disability, 3= Moderate pain, low/ moderate disability, 4= High intensity pain, high disability, severely limiting)

MYS = secondary myalgia pain/extension scale, $(0=$ no pain, $1=$ local pain at palpation site, $2=$ pain spreading beyond palpation site within the palpated muscle, 3 = pain spreading beyond palpation site and beyond the palpated muscle)

$M D=$ Mid-line deviation in maximum opening $(0=n o$ shift, $1=1 \mathrm{~mm}, 2=2 \mathrm{~mm}, 3=3 \mathrm{~mm}, 4=4 \mathrm{~mm})$.

Mean $=X$, Standard deviation $=S D, P=$ comparison with pre-treatment status, $P *=$ statistically significant difference when value is $(<0.001)$

$C V=$ coefficient of variation ( ratio of the standard deviation to the mean)

\section{RESULTS}

The patients' examination outcomes (table2) were significantly $(\mathrm{P} \leq 0.05)$ improved in Pain \& discomfort for both frequency and degree. The pain was significantly reduced in frequency from the pre-operative $(1.58 \pm 0.66)$ when compared to post-operative $(0.41 \pm 0.51)$ with a coefficient of variation $(\mathrm{CV})$ of 0.42 and 1.23 respectively. The pain was significantly reduced in degree from the pre-operative $(1.00 \pm 0.73)$ when compared to post-operative $(0.25 \pm 0.45)$ with a coefficient of variation $(\mathrm{CV})$ of 0.73 and 1.80 respectively. The pain modification was significantly reduced by chewing, movement, para-function, and others (this refers to psychological stress or anger attacks and sometimes other physical pain) from the preoperative $(0.58 \pm 0.51,0.50 \pm 0.52,0.75 \pm 0.45$, and $0.83 \pm 0.38)$ when compared to post-operative $(0.08 \pm 0.28,0.25 \pm 0.45,0.25 \pm 0.45$, and $0.16 \pm 0.38)$. Pre-operative CVs were $0.88,1.04,0.60$, and 0.46 and the post-operative CVs were $3.46,1.80,1.80$, and 2.33 respectively.

The patients' examination outcomes (table3) were significantly $(\mathrm{P} \leq 0.05)$ improved in MCPS, 
MYS, and MD. The MCPS was significantly ( $\mathrm{P} \leq$ $0.05)$ improved in 6 weeks $(0.58 \pm 0.51)$ and 12 weeks period $(0.25 \pm 0.45)$ in comparison to the starting point $(1.91 \pm 0.66)$. but the coefficient of variance was increased in the examination results for the pain/ disability scale and myalgia pain scale, especially in 12 weeks period. The MYS was significantly $(\mathrm{P} \leq 0.05)$ improved in 6 weeks $(0.58 \pm 0.51)$ and 12 weeks $(0.25 \pm 0.45)$ in comparison to the starting point $(1.33 \pm 0.65)$. The MD was significantly ( $\mathrm{P} \leq$ $0.05)$ improved in 6 weeks $(1.91 \pm 0.66)$ and 12 weeks period $(0.58 \pm 0.51)$ in comparison to the starting point $(3.08 \pm 0.51)$.

In table 4; A) the VAS results were significant between the starting point (7.00-7.85) and both 6 weeks (2.1-3.6) and 12 weeks (1.8-2.4) in a male/ female order, $\mathbf{B}$ ) the range of mandibular movement results was significantly $(\mathrm{P} \leq 0.05)$ improved in MMO, FMO, ILE, CLE, PE. i) the MMO range (in a female/ male order) was significantly improved in 12 weeks (34.3-39.7) in comparison to the starting point (29.2-33.5). ii) the FMO range (in a female/ male order) was significantly improved in 12 weeks (35.4-41.6) in comparison to the starting point (30.5-35.3). iii) the CLE range (in a female/ male order) was significantly improved in 12 weeks (3.80-4.80) in comparison to the starting point (5.00$6.50)$. iv) the ILE range (in a female/ male order) was significantly improved in 12 weeks (3.6-4.2) in comparison to the starting point (4.9-5.9). v) the PE range (in a female/ male order) was improved significantly in 12 weeks (6.20-6.20) in comparison to the starting point $(8.40-8.70)$. C) Helkimo's disability index was significantly improved (in a female/ male order) in comparison to the starting point (6.75-6.30), the score was (2.75-1.80) in the 6 weeks and (1.55-1.50) the 12 weeks. Also, significant improvement in 6 months (1.80-1.60) compared to the 3 months point (1.70-1.46) but no significant improvement in 12 months $(0.80-0.20)$ when compared with the 6 months.
TABLE (4): comparing pre- and post-treatment effect on study subjects (by gender) showing; VAS, maximum active and PMO, Contra LE, Ipsi LE, PE, Helkimo anamnestic and clinical dysfunction index.

\begin{tabular}{|c|c|c|c|c|}
\hline \multirow{2}{*}{$\begin{array}{l}\text { Categories } \\
\text { Per period }\end{array}$} & \multirow{2}{*}{ Gender } & \multicolumn{2}{|c|}{$\mathrm{X} \pm \mathrm{SD}$} & \multirow{2}{*}{$\mathrm{P}$} \\
\hline & & Pre & Post & \\
\hline \multirow{2}{*}{$\begin{array}{l}\text { VAS pain } \\
(0-6) \text { weeks }\end{array}$} & Female & $7.85 \pm 0.93$ & $3.6 \pm 3.05$ & $0.000^{*}$ \\
\hline & Male & $7.00 \pm 1.05$ & $2.1 \pm 1.85$ & $0.000^{*}$ \\
\hline \multirow{2}{*}{$\begin{array}{c}\text { VAS pain } \\
(0-12) \text { weeks }\end{array}$} & Female & $7.85 \pm 0.93$ & $2.4 \pm 1.84$ & $0.000 *$ \\
\hline & Male & $7.00 \pm 1.05$ & $1.8 \pm 1.65$ & $0.000^{*}$ \\
\hline \multirow{2}{*}{$\begin{array}{l}\text { VAS disability } \\
(0-6) \text { weeks }\end{array}$} & Female & $7.76 \pm 1.39$ & $4.17 \pm 1.18$ & $0.004^{*}$ \\
\hline & Male & $6.76 \pm 1.42$ & $4.07 \pm 1.18$ & $0.006^{*}$ \\
\hline \multirow{2}{*}{$\begin{array}{l}\text { VAS disability } \\
(0-12) \text { weeks }\end{array}$} & Female & $7.76 \pm 1.39$ & $3.11 \pm 1.02$ & $0.002 *$ \\
\hline & Male & $6.76 \pm 1.42$ & $2.07 \pm 1.22$ & $0.001^{*}$ \\
\hline \multirow{2}{*}{$\begin{array}{c}\text { MMO } \\
(0-12) \text { weeks }\end{array}$} & Female & $33.2 \pm 7.35$ & $40.3 \pm 8.81$ & $0.000^{*}$ \\
\hline & Male & $36.5 \pm 8.44$ & $42.7 \pm 7.85$ & $0.000 *$ \\
\hline \multirow{2}{*}{$\begin{array}{c}\text { FMO } \\
(0-12) \text { weeks }\end{array}$} & Female & $33.5 \pm 7.72$ & $42.4 \pm 9.40$ & $0.000 *$ \\
\hline & Male & $36.3 \pm 9.25$ & $44.6 \pm 8.02$ & $0.000 *$ \\
\hline \multirow{2}{*}{$\begin{array}{c}\text { ILE } \\
(0-12) \text { weeks }\end{array}$} & Female & $3.6 \pm 1.18$ & $4.9 \pm 1.97$ & $0.000 *$ \\
\hline & Male & $4.2 \pm 1.39$ & $5.9 \pm 1.37$ & $0.000^{*}$ \\
\hline \multirow{2}{*}{$\begin{array}{c}\text { CLE } \\
(0-12) \text { weeks }\end{array}$} & Female & $3.80 \pm 1.49$ & $5.00 \pm 1.74$ & $0.000^{*}$ \\
\hline & Male & $4.80 \pm 1.30$ & $6.50 \pm 0.97$ & $0.001^{*}$ \\
\hline \multirow{2}{*}{$\begin{array}{c}\text { PE } \\
(0-12) \text { weeks }\end{array}$} & Female & $6.20 \pm 0.95$ & $8.40 \pm 1.63$ & $0.000 *$ \\
\hline & Male & $6.20 \pm 0.91$ & $8.70 \pm 0.87$ & $0.001^{*}$ \\
\hline \multirow{2}{*}{$\begin{array}{l}\text { Helkimo's Di } \\
\text { (0-6weeks) }\end{array}$} & Female & $6.75 \pm 1.20$ & $2.75 \pm 2.46$ & $0.000^{*}$ \\
\hline & Male & $6.30 \pm 1.25$ & $1.80 \pm 2.06$ & $0.000^{*}$ \\
\hline \multirow{2}{*}{$\begin{array}{l}\text { Helkimo's Di } \\
\text { (0-12weeks) }\end{array}$} & Female & $6.75 \pm 1.20$ & $1.55 \pm 1.66$ & $0.000^{*}$ \\
\hline & Male & $6.30 \pm 1.25$ & $1.50 \pm 1.44$ & $0.000^{*}$ \\
\hline \multirow{2}{*}{$\begin{array}{l}\text { Helkimo's Di } \\
\text { (12-24weeks) }\end{array}$} & Female & $1.80 \pm 0.36$ & $1.70 \pm 0.46$ & $0.000^{*}$ \\
\hline & Male & $1.60 \pm 0.51$ & $1.46 \pm 0.51$ & $0.000^{*}$ \\
\hline \multirow{2}{*}{$\begin{array}{l}\text { Helkimo's Di } \\
\text { (24-52weeks) }\end{array}$} & Female & $1.80 \pm 0.36$ & $0.80 \pm 0.89$ & 0.082 \\
\hline & Male & $1.60 \pm 0.51$ & $0.20 \pm 0.63$ & 0.163 \\
\hline
\end{tabular}

* significant when $p<.05, V A S=$ Visual analog scale, $M M O=$ maximum mouth opening, FMO = dentist assessed mouth opening, CLE = contra-lateral excursion, ILE = Ipsi-lateral excursion, $P E=$ Protrusive excursion, Helkimo's Dysfunction index (Di). 


\section{DISCUSSION}

Based on statistical interpretation of results, the null hypnosis was accepted. The diagnosis protocol is according to the original RDC/TMD ${ }^{(56)}$ and its updates ${ }^{(74)}$. The incorporated categories were; a) history (self-evaluation with minor staff assistance in "form1"), b) examination ( clinical examination by the same examiner using "form 2"), c) radiographic examination (MRI images produced by the same machine and examined by the same radiologist) ${ }^{(75,76)}$.

The treatment protocol started with ARS instead of a centric splint. In literature, the centric splint was reported as a treatment modality in TMD cases ${ }^{(77)}$ to decrease symptoms of OFP more efficiently than distraction splints ${ }^{(78)}$. Nevertheless, the centric mandibular splint reduced pain by altering the pain processing and anticipation ${ }^{(79)}$, and it was not confirmed to assess disc-condyle spatial relation enhancement ${ }^{\left({ }^{80}\right)}$.

Although, some reports questioned the effectiveness of the splint therapy and claimed a low quality confirming evidence of that treatment protocol ${ }^{(79)}$. MCPS, MYS, and MD showed a significant reduction in 6-weeks and 12-weeks follow-up. Those results support the positive effect of the ARS on the cases of this study. And agrees with the ARS reported to efficient control \& reduction of all symptoms of OFP in most TMD cases ${ }^{(\mathbf{8 2})}$. Also, patients' improvement of $88 \%$ and $92 \%$ treatment efficiency proved through MRI examination ${ }^{(54,55,56,72)}$.

ARS with positive anterior teeth indentation in protrusive mandible position and faint posterior indentation used in the first three months, before transformation to a stabilization splint for the successive nine months. The ARS positive indentation was reported superior to the flat-plane splints (stabilization splints) in myalgia and joint clicking and tenderness reduction ${ }^{(72,73,83)}$. In the first few days, some patients reported difficulty maintaining the protrusive position recorded by anterior indentations. The splint thickness was not less than $3 \mathrm{~mm}$ in all treatment phases to assure better results ${ }^{(\mathbf{8 4})}$.

\section{Patient self-evaluation outcome.}

All the patients were committed to the scheduled follow-up with no dropouts. The short period of ARS use (3 months) helped to enhance the case generally and the reduction of muscle pain, joint pain, clicking, pain modification factors, and jaw dysfunction. The patient's 12-weeks self-evaluations significantly improved.

These findings agreed with other studies that used the ARS for 2-3 months, considering it a highly recommended non-invasive approach ${ }^{(85-87)}$. Patientreported pain frequency and degree significantly decreased. The pain evoked by a modification was reduced as well.

Those results agree with other studies that reported comparable outcomes in 3 months ${ }^{(44,45,88,89,90)}$. And with Raphael. et al. ${ }^{(91)}$. They found a reduction in pain evoked by a modification (swallowing, speaking, emotional stress, etc) by the use of ARS in 6 weeks use. But the reduction was more significant in localized pain.

Nilner. et al. ${ }^{(92)}$ reported a $50 \%$ worst pain reduction in 55\% of patients after 6-weeks ARS use and a $61 \%$ worst pain reduction in $69 \%$ of patients after 10 -weeks. Oliveira et al. ${ }^{(93)}$ and Wahlund K. ${ }^{(94)}$ reported a $60 \%$ worst pain reduction in $50 \%$ of patients, and Others found a better outcome regarding pain intensity and frequency.

Madani. et al. ${ }^{(88)}$ reported a $60 \%$ disappearance and $35 \%$ modification of subjective pain with a $50 \%$ reduction of perceived pain and disability caused by pain ${ }^{(95)}$. Behr. et al. ${ }^{(96)}$ reported a pain reduction in $66 \%$ of patients after 1 -year of therapy. In 5 months ARS use, Daif ET. ${ }^{(97)}$ reported an $85 \%$ improvement (either completely recovered $35 \%$ or clinically improved 50\%). 


\section{Patient examination outcome}

\section{Pain/disability}

The pain/disability scale results, mandibular deviation results, and myogenic pain results decreased significantly. That agrees with other clinical reports on the used clinical examination parameters improvement ${ }^{(98,99,100,101)}$. Al Quran. et al. ${ }^{(102)}$ reported $56.66 \%$ pain/disability reduction. Fernandes. et al. ${ }^{(103)}$ also reported a pain/ disability reduction by oral splint use.

\section{Myalgia}

Myogenic pain (muscle-related pain) is usually a primary finding that leads (after comprehensive diagnosis) to reach the final, precise diagnosis of TMD and its type ${ }^{(104)}$. TMD and myalgia are coexisting, interrelated components, in which myalgia may be the second TMD's main ingredient ${ }^{(\mathbf{1 0 5})}$. In TMD cases, the etiology of masticatory muscles myalgia is still unclear.

Muscles' parafunction and harmful oral habits are a suggested cause of muscles tissue injury ${ }^{(15)}$. The results showed the myogenic pain score (range from 0-2) at the pre-treatment phase, which indicated a maximum pain localized within the palpable muscle (within or beyond the palpated area). According to Raphael. et al. ${ }^{(91)}$, the oral splint is effective in localized myogenic pain reduction than the widespread pain type.

\section{Mandibular Deviation}

The mandibular deviation was improved significantly by ARS. In literature, the hypothesized etiology of the mandibular deviation or the modified jaw movement path results from myalgia due to; a) abnormal function which modifies the muscle action to least painful alternative ${ }^{(15,106)}$, or b) a modified muscle action in response to impulses from TMJ

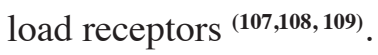

\section{Occlusion}

The stomatognathic system usually adapts to early asymptomatic pathologic changes of TMD ${ }^{(110)}$.
Some study subjects showed a) defective posterior maximum intercuspation, b) mediolateral occlusal deflection/slide, or c) mid-line deviation. presented at the beginning and the end of the masticatory cycle during condyle-disc translator part of mouth opening.

No occlusal adjustments were considered for any patient. A statistically significant decrease in midline deviation was apparent during the successive study periods. The occlusal slide/deflection decreased by the progress in treatment and the decrease of symptoms and pain.

The deviation on opening may have created the illusion of occlusal slide upon closure, thus the decrease in deviation consequently made the slide/ deflection less noticed by the progress of treatment. Also, during the active disease course, the myogenic pain and the muscle spasm usually alter the mandibular path upon opening and alter the posterior teeth contact pattern. Usually the patient shelters to the least painful path of opening and closure and seeks the least painful pattern of teeth contact and masticatory cycle.

In literature, the occlusal adjustments in symptomatic TMDs were seldom advised, because; 1) occlusal slide may be a consequence of TMD rather than an etiology, 2) occlusal variables are of low relative risk in TMD development ${ }^{(111)}$. Also, there was no statistically confirmed cause-effect relation between occlusal features and TMDs ${ }^{(112)}$.

Also, 3-month use of ARS was recommended by Conti. et al. ${ }^{(73)}$ to avoid the development of posterior open bite ${ }^{(113)}$, thus the conversion to partial time use with a stabilization splint is recommended and justified.

\section{Clinical follow-up results.}

\section{VAS score}

The used VAS was a 10-centimeter scale, VAS of pain showed an improvement from 7 to 2.1 in 6 weeks and reached 1.8 in 3 months. 
Many studies reported a significant VAS improvement after ARS use ${ }^{\mathbf{( 9 0 , 1 1 4 , 1 1 5 )}}$. Although changes were significant. This could be accepted because, in subjective-score templates, the results could be affected by social status, economic status, educational level, and gender-wise. According to Linton \& Gotestam ${ }^{(116)}$, patients have a general tendency to overestimate the pain VAS scores regarding duration and intensity, especially in the baseline.

In literature, some studies used a 10-points scale while others used a 100-points scale. Madani et al ${ }^{(88)}$, reported a similar VAS enhancement from 61 to 36.5 in 3 months treatment period. Also, Sousa $\mathrm{BM}$ et al. ${ }^{(117)}$, reported an improved VAS, started at 7.1 and reached $1.4 \& 0.7$ in 1 month and 6 months respectively. Di Paolo et al ${ }^{\left({ }^{118)}\right.}$, reported VAS scores improvement from 63 to 8.32 , and $70 \%$ of their patients considered themselves healed.

Zhigui et al. ${ }^{(82)}$, reported pain VAS of $3.89 \pm 1.80$, $2.23 \pm 1.77$, and $1.37 \pm 1.57$ in baseline, 3months, and 1 year respectively. Badel T. et al ${ }^{(100)}$, reported a pain VAS scores reduction from 5.589 (at baseline) to 2.054 and 0.41 at 4 weeks and 16 weeks respectively. Dao et al. ${ }^{(119)}$ found a decrease in VAS of pain intensity at rest and after exercise in 8 weeks ARS use.

VAS disability scores showed an improvement from 6.7-7.7 to 4, and 2-3 in 6, and 12 weeks. Zhigui et al. ${ }^{\left({ }^{82}\right)}$ reported a mean disability VAS reduction from 4.42 to 3.66 and 2.50 in 3months, and 1 year respectively. Riley P et al. ${ }^{(\mathbf{1 2 0})}$ reported a pain VAS reduction of 1.40 to 2.01 at the end of treatment.

\section{Range of motion}

MMO has changed significantly from 33$36 \mathrm{~mm}$ up to $7-8 \mathrm{~mm}$ improvement. The mandibular functional range showed a significant increase in

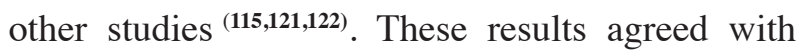
Zhang C. et al.'s ${ }^{(82)}$ results that found a $5-5.4 \mathrm{~mm}$ increase in cases with an initial MMO $<37 \mathrm{~mm}$. Sousa BM. et al. ${ }^{(117)}$ reported a change of $8-9 \mathrm{~mm}$ in pain-free MMO started at $26.8 \mathrm{~mm}$ to became $34.7 \mathrm{~mm}$ and $35.6 \mathrm{~mm}$ in 1-month and 6-months.

According to De Felicio et al. ${ }^{(\mathbf{1 2 3})}$, the MMO had a minor change (1-2mm), but the ILE, CLE, and PE were changed from $(42.33,6.26,7.33$, and $5.08)$ to $(43.96,6.84,8.55$, and 6.99$)$ respectively. While Zhigui. et al. ${ }^{(\mathbf{8 2})}$ reported no improvement in the tested parameters of the mandibular functional range.

\section{Helkimo's Di}

In 123 TMD cases (93 females, 30 males), Polso HL. et al. ${ }^{(124)}$ reported a significant decrease in Helkimo's Di after the ARS treatment. Daif. et al. ${ }^{(97)}$ also mentioned better clinical dysfunction indices on 6-months with splint therapy.

Magnusson T. \& Syren M. ${ }^{(125)}$ also reported a significant improvement in Di over a 6-months use of stabilization splint. And Ekberg. et al. ${ }^{(126)}$ inferred a better Di index in 10 weeks of stabilization splint at night only. The reports agreed with the Di indices improvement concerning the short-term ARS use and stabilization splint in the short-\& long-term. Although the Di index offered a supportive piece of information with significant results and agreed with other studies, most of the studies lacked a precise description of treatment and follow-up times.

\section{Clicking sounds}

Tallents. et al. ${ }^{(113)}$ reported clicking-sound categories based on the timing and the amount of vertical jaw separation.

Accordingly, the cases contributed in this study were as follows; A) according to vertical jaw opening (a $60 \%$ of the patients had an early clicking and $40 \%$ had a mid-click), and B) according to clicking timing during jaw opening (an 83\% earlytype and $17 \%$ and mid-type).

All the patients reported a clicking TMJ sound (at least unilaterally). A $75 \%$ of the patients reported the disappearance of clicking sounds in the first 
two weeks of treatment, and $100 \%$ mentioned the complete absence of the clicking in $\leq 4$ weeks.

Conti. et al. ${ }^{(127)}$ reported a $100 \%$ improvement of clicking sound with ARS use within the first 2 -weeks and only $67 \%$ for another splint type.

Some authors explained the resolution of sounds by the disc morphological alterations ${ }^{(128)}$, while others considered it a progressive adaptation or natural healing process ${ }^{(\mathbf{9 3}, \mathbf{1 2 9})}$.

\section{MRI}

During the MRI follow-up in 3 months and one year, the MRI demonstrated the signs of disc recapture (return to normal position) in $66 \%$ of cases, while nearly $34 \%$ attained a partial recapture (especially in the TMJ affected side). The backward movement of the disc can result from the condyle forward and downward position, so the ARS helped maintain a normal disc-condyle relationship. The one-year MRI revealed 83\% disc recapture and 17\% resistance cases of partial recapture. According to the results, the conversion of ARS did not disturb the course of treatment or jeopardize the disc recapture process.

Some authors described the progressive splints as a short-term solution for DDwR and reported a risk of disc recapture failure and recurrence upon the ARS removal ${ }^{(130,131)}$. Contrarily, a stabilized case was reported and confirmed through MRI after 2-year treatment. Hence the long period disc recapture stability helps to encourage the adaptation tissues synthesis (formation of extra fibrous tissues and increased the thickness of the disc tissues) ${ }^{\left({ }^{(29)} \text {. }\right.}$

In this work, the splint was not removed (withdrawn) after three months. Instead, it was modified (as a stabilization splint) for part-time use in the successive nine months. Therefore, disc recurrence possibility ${ }^{\left({ }^{130)}\right.}$ and the risk of keeping the mandible in anterior displacement reduced ${ }^{(72,73)}$, securing a better result. According to Zhigui. et al. ${ }^{\left({ }^{82}\right)}$ a $92.31 \%$ disc-recapture success was reported after 3-months of ARS treatment. That decreased to $72.53 \%$ after 1 -year of treatment stop and ARS removal.

Also, the ongoing improvements in all clinical parameters in 6-months and 1-year therapy could have resulted from a) elimination of pressure on disc tissues, b) stretching of joint-associated ligaments and muscles, c) reduction of motor activity in masticatory muscles ${ }^{(47,48,49,132)}$.

A2-month use of the ARS reported accomplishing MRI proved a $70 \%$ displaced-discs reduction ${ }^{(133)}$. Kurita. et al. ${ }^{(134)}$ reported a $50 \%$ disc-recapture at the end of the treatment and resolution of all signs and symptoms. Liu. et al. ${ }^{\left({ }^{80}\right)}$ also mentioned a more posterior disc movement $(2.23 \mathrm{~mm})$ in the ARS group and less $(0.75 \mathrm{~mm})$ for the stabilization splint.

Some cases showed resistance in disc-recapture. Other reports also investigated the use of ARS in severe cases of joint derangement and found a reduction of OFP symptoms with no MRI signs of normal disc-condyle relationship ${ }^{(135)}$. Severe disk displacement is not necessarily pure anterior and may contain a transverse component which renders the ARS much less effective $(56,136,137,138,139)$.

According to Kurita. et al. ${ }^{(140)}$ the DD joints with persisting non-recapture discs were usually associated with; A) deformed, flattened articular eminence, and B) condylar deformation or size regression. The disc-recapture resistance occurs despite being irrelevant to the resolution of all signs and symptoms. In severe joint internal derangement, Katzberg. et al. ${ }^{(141)}$ and Ronquillo et al. ${ }^{(142)}$ reported an abnormal condylar position (posterior dislocation) even in centric occlusion.

\section{CONCLUSION}

In conclusion, the day and night use of ARS provided an improvement in all investigated parameters and was considered a successful treatment for DDwR. The continuous use of modified ARS into a stabilizing splint is beneficial 
to the patient with no recorded patient complaint or any adverse effect on jaw function.

MRI (complete or partial) disc-recapture through the ARS therapy and its modification achieved. Nevertheless, the regression of signs and symptoms was not directly associated with and sometimes preceded that recapture.

Also, a further investigation is required to disclose the possibility of recurrence of signs and symptoms, or disc-recapture failure, after modified ARS removal.

\section{Conflict of interest}

The authors declare no conflict of interest.

\section{REFERENCES}

1. Shaffer SM, Brismée JM, Sizer PS, Courtney CA. Temporomandibular disorders. Part 1: anatomy and examination/diagnosis. J Man Manip Ther. 2014;22(1):2-12.

2. Forssell H, Kalso E. Application of principles of evidencebased medicine to occlusal treatment for temporomandibular disorders: are there lessons to be learned? J Orofac Pain. 2004;18(1):9-22.

3. Srivastava R, Jyoti B, Devi P. Oral splint for temporomandibular joint disorders with revolutionary fluid system. Dent Res J (Isfahan). 2013;10(3):307-13.

4. De Leeuw R, Klasser GD. Orofacial pain: guidelines for assessment, diagnosis, and management. Am J Orthod Dentofacial Orthop. 2008;134(1):171.

5. Renton T, Durham J, Aggarwal VR. The classification and differential diagnosis of orofacial pain. Expert Rev Neurother. 2012;12(5):569-76.

6. Nixdorf DR, Drangsholt MT, Ettlin DA, Gaul C, De Leeuw R, Svensson P, Zakrzewska JM, De Laat A, Ceusters W; International RDC-TMD Consortium. Classifying orofacial pains: a new proposal of taxonomy based on ontology. J Oral Rehabil. 2012;39(3):161-9.

7. Gauer RL, Semidey MJ. Diagnosis and treatment of temporomandibular disorders. Am Fam Physician. 2015;91(6):378-86.

8. Gremillion HA. Multidisciplinary diagnosis and management of orofacial pain. General dentistry. 2002 $1 ; 50(2): 178-89$.
9. Durham J, Raphael KG, Benoliel R, Ceusters W, Michelotti A, Ohrbach R. Perspectives on next steps in classification of oro-facial pain - part 2: role of psychosocial factors. J Oral Rehabil. 2015;42(12):942-55.

10. Scrivani SJ, Spierings EL. Classification and Differential Diagnosis of Oral and Maxillofacial Pain. Oral Maxillofac Surg Clin North Am. 2016;28(3):233-46.

11. Ghurye S, McMillan R. Orofacial pain - an update on diagnosis and management. Br Dent J. 2017;223(9):639-647.

12. Zakrzewska JM. Differential diagnosis of facial pain and guidelines for management. Br J Anaesth. 2013;111(1): 95-104.

13. Elliott AM, Smith BH, Penny KI, Smith WC, Chambers WA. The epidemiology of chronic pain in the community. The lancet. 1999;354(9186):1248-52.

14. Anderson GC, Gonzalez YM, Ohrbach R, Truelove EL, Sommers E, Look JO, Schiffman EL. The Research Diagnostic Criteria for Temporomandibular Disorders. VI: future directions. J Orofac Pain. 2010;24(1):79-88.

15. Valentino R, Cioffi I, Vollaro S, Cimino R, Baiano R, Michelotti A. Jaw muscle activity patterns in women with chronic TMD myalgia during standardized clenching and chewing tasks. Cranio. 2021;39(2):157-63.

16. Abdalla-Aslan R, Shilo D, Nadler C, Eran A, Rachmiel A. Diagnostic correlation between clinical protocols and magnetic resonance findings in temporomandibular disorders: A systematic review and meta-analysis. J Oral Rehabil. 2021;48(8):955-967.

17. Dinsdale A, Forbes R, Thomas L, Treleaven J. "What if it doesn't unlock?": A qualitative study into the lived experiences of adults with persistent intra-articular temporomandibular disorders. Musculoskelet Sci Pract. 2021;54:102401.

18. The Glossary of Prosthodontic Terms: Ninth Edition. J Prosthet Dent. 2017;117(5S):e1-e105.

19. Tanaka E, Detamore MS, Mercuri LG. Degenerative disorders of the temporomandibular joint: etiology, diagnosis, and treatment. J Dent Res. 2008;87(4):296-307.

20. Cuccia A, Caradonna C. The relationship between the stomatognathic system and body posture. Clinics (Sao Paulo). 2009;64(1):61-6.

21. Bourdiol P, Hennequin M, Peyron MA, Woda A. Masticatory Adaptation to Occlusal Changes. Front Physiol. 2020;(3)11:263. 
22. Clark JR, Evans RD. Functional occlusion: I. A review. J Orthod. 2001;28(1):76-81.

23. Warreth A, Doody K, Al-Mohsen M, Morcos O, AlMohsen M, Ibieyou N. Fundamentals of occlusion and restorative dentistry. Part II: occlusal contacts, interferences and occlusal considerations in implant patients. J Ir Dent Assoc. 2015;61(5):252-9.

24. Le Bell Y, Niemi PM, Jämsä T, Kylmälä M, Alanen P. Subjective reactions to intervention with artificial interferences in subjects with and without a history of temporomandibular disorders. Acta Odontol Scand. 2006;64(1):59-63.

25. Lobbezoo F, Ahlberg J, Manfredini D, Winocur E. Are bruxism and the bite causally related? J Oral Rehabil. 2012;39(7):489-501.

26. Xie Q, Li X, Xu X. The difficult relationship between occlusal interferences and temporomandibular disorder - insights from animal and human experimental studies. J Oral Rehabil. 2013;40(4):279-95.

27. Kandasamy S, Greene CS, Obrez A. An evidence-based evaluation of the concept of centric relation in the $21 \mathrm{st}$ century. Quintessence Int. 2018;49(9):755-60.

28. Marzooq AA, Yatabe M, Ai M. What types of occlusal factors play a role in temporomandibular disorders...? A literature review. J Med Dent Sci. 1999;46(3):111-6.

29. Caldas W, Conti AC, Janson G, Conti PC. Occlusal changes secondary to temporomandibular joint conditions: a critical review and implications for clinical practice. J Appl Oral Sci. 2016;24(4):411-9.

30. Eder J, Szomolanyi P, Schmid-Schwap M, Bristela M, Skolka A, Pittschieler E, Piehslinger E, Trattnig S. Early diagnosis of degenerative changes in the articular/fibrocartilaginous disc of the temporomandibular joint in patients with temporomandibular disorders using delayed gadolinium-enhanced MRI at 3 Tesla - preliminary results. Magn Reson Imaging. 2020;67:24-27.

31. Österlund C, Berglund H, Åkerman M, Nilsson E, Petersson H, Lam J, Alstergren P. Diagnostic criteria for temporomandibular disorders: Diagnostic accuracy for general dentistry procedure without mandatory commands regarding myalgia, arthralgia and headache attributed to temporomandibular disorder. J Oral Rehabil. 2018;45(7):497-503.

32. Ruscheweyh R, Becker T, Born Y, Çolak-Ekici R, Marziniak M, Evers S, Gerlach AL, Wolowski A. Effects of stress and relaxation on pain perception in subjects with pain-free occlusional disharmony compared with healthy controls. Oral Dis. 2015;21(3):400-7.

33. Greene CS, Manfredini D. Transitioning to chronic temporomandibular disorder pain: A combination of patient vulnerabilities and iatrogenesis. J Oral Rehabil. 2021;48(9):1077-88.

34. Inui M, Fushima K, Sato S. Facial asymmetry in temporomandibular joint disorders. J Oral Rehabil. 1999;26(5):402-6.

35. Ohrbach R, Dworkin SF. The Evolution of TMD Diagnosis: Past, Present, Future. J Dent Res. 2016;95(10):1093101.

36. Litt MD, Shafer DM, Kreutzer DL. Brief cognitive-behavioral treatment for TMD pain: long-term outcomes and moderators of treatment. Pain. 2010;151(1):110-16.

37. Vranceanu AM, Shaefer JR, Saadi AF, Slawsby E, Sarin J, Scult M, Benson H, Denninger JW. The Relaxation Response Resiliency Enhancement Program in the Management of Chronic Refractory Temporomandibular Joint Disorder: Results from a Pilot Study. J Musculoskelet Pain. 2013;21(3):224-30.

38. Cairns BE. Pathophysiology of TMD pain--basic mechanisms and their implications for pharmacotherapy. J Oral Rehabil. 2010;37(6):391-410.

39. Dimitroulis G. Management of temporomandibular joint disorders: A surgeon's perspective. Aust Dent J. 2018;63(1):S79-S90.

40. McNeely ML, Armijo Olivo S, Magee DJ. A systematic review of the effectiveness of physical therapy interventions for temporomandibular disorders. Phys Ther. 2006;86(5):710-25.

41. Pierson MJ. Changes in temporomandibular joint dysfunction symptoms following massage therapy: a case report. Int J Ther Massage Bodywork. 2011;4(4):37-47.

42. de Félicio CM, Freitas RL, Bataglion C. The effects of orofacial myofunctional therapy combined with an occlusal splint on signs and symptoms in a man with TMDhypermobility: case study. Int J Orofacial Myology. 2007; 33:21-9.

43. Michelotti A, Iodice G, Vollaro S, Steenks MH, Farella M. Evaluation of the short-term effectiveness of education versus an occlusal splint for the treatment of myofascial pain of the jaw muscles. J Am Dent Assoc. 2012;143(1):47-53. 
44. Ekberg E, Vallon D, Nilner M. The efficacy of appliance therapy in patients with temporomandibular disorders of mainly myogenous origin: a randomized, controlled, shortterm trial. J Orofac Pain 2003;17(2):133-39.

45. Ekberg E, Nilner M. Treatment outcome of appliance therapy in temporomandibular disorder patients with myofascial pain after 6 and 12 months. Acta Odontol Scand 2004;62(6):343-49.

46. Ekberg EC, Nilner M. Treatment outcome of short- and long-term appliance therapy in patients with TMD of myogenous origin and tension-type headache. J Oral Rehabil. 2006;33(10):713-21.

47. Tsukiyama Y, Baba K, Clark GT. An evidence-based assessment of occlusal adjustment as a treatment for temporomandibular disorders. J Prosthet Dent. 2001;86(1): 57-66.

48. Klasser GD, Greene CS. Oral appliances in the management of temporomandibular disorders. Oral Surg Oral Med Oral Pathol Oral Radiol Endod. 2009;107(2):212-23.

49. Greene CS, Menchel HF. The Use of Oral Appliances in the Management of Temporomandibular Disorders. Oral Maxillofac Surg Clin North Am. 2018;30(3):265-77.

50. Riolo ML, Brandt D, TenHave TR. Associations between occlusal characteristics and signs and symptoms of TMJ dysfunction in children and young adults. Am J Orthod Dentofacial Orthop. 1987;92(6):467-77.

51. Kuć J, Szarejko KD, Gołebiewska M. Smiling, Yawning, Jaw Functional Limitations and Oral Behaviors With Respect to General Health Status in Patients With Temporomandibular Disorder-Myofascial Pain With Referral. Front Neurol. 2021 24;12:646293.

52. Sinha VP, Pradhan H, Gupta H, Mohammad S, Singh RK, Mehrotra D, Pant MC, Pradhan R. Efficacy of plain radiographs, CT scan, MRI and ultra sonography in temporomandibular joint disorders. Natl J Maxillofac Surg. 2012;3(1):2-9.

53. Jo JH, Bae S, Gil J, Oh D, Park S, Cheon GJ, Park JW. Limited implication of initial bone scintigraphy on longterm condylar bone change in temporomandibular disorders-Comparison with cone beam computed tomography at 1 year. J Oral Rehabil. 2021;48(8):880-890.

54. Simmons HC 3rd, Gibbs SJ. Initial TMJ disk recapture with anterior repositioning appliances and relation to dental history. Cranio. 1997;15(4):281-95.
55. Ahmad M, Hollender L, Anderson Q, Kartha K, Ohrbach R, Truelove EL, John MT, Schiffman EL. Research diagnostic criteria for temporomandibular disorders (RDC/ TMD): development of image analysis criteria and examiner reliability for image analysis. Oral Surg Oral Med Oral Pathol Oral Radiol Endod. 2009;107(6):844-60.

56. Ikeda K, Kawamura A. Disc displacement and changes in condylar position. Dentomaxillofac Radiol. 2013; 42(3):84227642.

57. Gonzalez YM, Schiffman E, Gordon SM, Seago B, Truelove EL, Slade G, Ohrbach R. Development of a brief and effective temporomandibular disorder pain screening questionnaire: reliability and validity. J Am Dent Assoc. 2011;142(10):1183-91.

58. Dworkin SF, LeResche L. Research diagnostic criteria for temporomandibular disorders: review, criteria, examinations and specifications, critique. J Craniomandib Disord. 1992;6(4):301-55.

59. Manfredini D, Chiappe G, Bosco M. Research diagnostic criteria for temporomandibular disorders (RDC/TMD) axis I diagnoses in an Italian patient population. J Oral Rehabil. 2006;33(8):551-8.

60. Landi N, Manfredini D, Tognini F, Romagnoli M, Bosco M. Quantification of the relative risk of multiple occlusal variables for muscle disorders of the stomatognathic system. J Prosthet Dent. 2004;92(2):190-5.

61. Walton TR, Layton DM. Mediotrusive Occlusal Contacts: Best Evidence Consensus Statement. J Prosthodont. 2021;30(S1):43-51.

62. Mongini F, Italiano M. TMJ disorders and myogenic facial pain: a discriminative analysis using the McGill Pain Questionnaire. Pain. 2001;91(3):323-30.

63. Kogawa EM, Calderon PD, Lauris JR, Pegoraro LF, Conti PC. Evaluation of minimum interdental threshold ability in dentate female temporomandibular disorder patients. J Oral Rehabil. 2010;37(5):322-8.

64. Meyer RA. The Temporomandibular Joint Examination. In: Walker HK, Hall WD, Hurst JW, editors. Clinical Methods: The History, Physical, and Laboratory Examinations. 3rd ed. Boston: Butterworths; 1990. Chapter 163.

65. Kim SG, Lim H, Chang CN, Lo LJ. Jaw deviation and ankylosis caused by condylar osteochondroma: long-term treatment outcome. J Oral Maxillofac Surg. 2014;72(3):604. 
66. Suvinen TI, Reade PC, Kemppainen P, Könönen M, Dworkin SF. Review of aetiological concepts of temporomandibular pain disorders: towards a biopsychosocial model for integration of physical disorder factors with psychological and psychosocial illness impact factors. Eur J Pain. 2005;9(6):613-33.

67. Helkimo M. Studies on function and dysfunction of the masticatory system. II. Index for anamnestic and clinical dysfunction and occlusal state. Sven Tandlak Tidskr. 1974;67(2):101-21.

68. Alonso-Royo R, Sánchez-Torrelo CM, Ibáñez-Vera AJ, Zagalaz-Anula N, Castellote-Caballero Y, Obrero-Gaitán E, Rodríguez-Almagro D, Lomas-Vega R. Validity and Reliability of the Helkimo Clinical Dysfunction Index for the Diagnosis of Temporomandibular Disorders. Diagnostics (Basel). 2021;11(3):472.

69. Garcia AR, Folli S, Zuim PR, de Sousa V. Mandible protrusion and decrease of TMJ sounds: an electrovibratographic examination. Braz Dent J. 2008; 19(1):77-82.

70. Huang IY, Wu JH, Kao YH, Chen CM, Chen CM, Yang YH. Splint therapy for disc displacement with reduction of the temporomandibular joint. part I: modified mandibular splint therapy. Kaohsiung J Med Sci. 2011;27(8):323-9.

71. Wu JH, Kao YH, Chen CM, Shu CW, Chen CM, Huang IY. Modified mandibular splint therapy for disc displacement with reduction of the temporomandibular joint. Journal of dental sciences. 2013;8(1): 91-93.

72. Davies SJ, Gray RJ. The pattern of splint usage in the management of two common temporomandibular disorders. Part I: The anterior repositioning splint in the treatment of disc displacement with reduction. Br Dent J. 1997;183(6):199-203.

73. Conti PC, Miranda JE, Conti AC, Pegoraro LF, Araújo Cdos R. Partial time use of anterior repositioning splints in the management of TMJ pain and dysfunction: a one-year controlled study. J Appl Oral Sci. 2005;13(4):345-50.

74. Schiffman E, Ohrbach R, Truelove E, Look J, Anderson G, Goulet JP, List T, Svensson P, Gonzalez Y, Lobbezoo F, Michelotti A, Brooks SL, Ceusters W, Drangsholt M, Ettlin D, Gaul C, Goldberg LJ, Haythornthwaite JA, Hollender L, Jensen R, John MT, De Laat A, de Leeuw R, Maixner W, van der Meulen M, Murray GM, Nixdorf DR, Palla S, Petersson A, Pionchon P, Smith B, Visscher CM, Zakrzewska J, Dworkin SF; International RDC/TMD Consortium Network, International association for Dental
Research; Orofacial Pain Special Interest Group, International Association for the Study of Pain. Diagnostic Criteria for Temporomandibular Disorders (DC/TMD) for Clinical and Research Applications: recommendations of the International RDC/TMD Consortium Network* and Orofacial Pain Special Interest Group $\dagger$. J Oral Facial Pain Headache. 2014;28(1):6-27.

75. Schiffman EL, Truelove EL, Ohrbach R, Anderson GC, John MT, List T, Look JO. The Research Diagnostic Criteria for Temporomandibular Disorders. I: overview and methodology for assessment of validity. J Orofac Pain. 2010;24(1):7-24.

76. Truelove E, Pan W, Look JO, Mancl LA, Ohrbach RK, Velly AM, Huggins KH, Lenton P, Shiffman EL. The Research Diagnostic Criteria for Temporomandibular Disorders. III: validity of Axis I diagnoses. J Orofac Pain. 2010;24(1):35-47.

77. Devi J, Verma M, Gupta R. Assessment of treatment response to splint therapy and evaluation of TMJ function using joint vibration analysis in patients exhibiting TMJ disc displacement with reduction: A clinical study. Indian J Dent Res. 2017;28(1):33-43.

78. Schmitter M, Zahran M, Duc JM, Henschel V, Rammelsberg P. Conservative therapy in patients with anterior disc displacement without reduction using 2 common splints: a randomized clinical trial. J Oral Maxillofac Surg. 2005;63(9):1295-303.

79. Ernst M, Schenkenberger AE, Domin M, Kordass B, Lotze M. Effects of centric mandibular splint therapy on orofacial pain and cerebral activation patterns. Clin Oral Investig. 2020;24(6):2005-13.

80. Liu MQ, Lei J, Han JH, Yap AU, Fu KY. Metrical analysis of disc-condyle relation with different splint treatment positions in patients with TMJ disc displacement. J Appl Oral Sci. 2017;25(5):483-89.

81. Al-Moraissi EA, Farea R, Qasem KA, Al-Wadeai MS, AlSabahi ME, Al-Iryani GM. Effectiveness of occlusal splint therapy in the management of temporomandibular disorders: network meta-analysis of randomized controlled trials. Int J Oral Maxillofac Surg. 2020;49(8):1042-56.

82. Ma Z, Xie Q, Yang C, Zhang S, Shen Y, Abdelrehem A. Can anterior repositioning splint effectively treat temporomandibular joint disc displacement? Sci Rep. 2019;9(1):534.

83. Zamburlini I, Austin D. Long-term results of appliance therapies in anterior disk displacement with reduction: a review of the literature. Cranio. 1991;9(4):361-8. 
84. Lin SL, Wu SL, Ko SY, Yen CY, Yang JW. Effect of FlatPlane Splint Vertical Thickness on Disc Displacement Without Reduction: A Retrospective Matched-Cohort Study. J Oral Maxillofac Surg. 2017;75(8):1627-36.

85. Tecco S, Festa F, Salini V, Epifania E, D'Attilio M. Treatment of joint pain and joint noises associated with a recent TMJ internal derangement: a comparison of an anterior repositioning splint, a full-arch maxillary stabilization splint, and an untreated control group. Cranio. 2004;22(3):209-19.

86. Ebrahim S, Montoya L, Busse JW, Carrasco-Labra A, Guyatt GH; Medically Unexplained Syndromes Research Group. The effectiveness of splint therapy in patients with temporomandibular disorders: a systematic review and meta-analysis. J Am Dent Assoc. 2012;143(8):847-57.

87. Zhang SH, He KX, Lin CJ, Liu XD, Wu L, Chen J, Rausch-Fan X. Efficacy of occlusal splints in the treatment of temporomandibular disorders: a systematic review of randomized controlled trials. Acta Odontol Scand. 2020;78(8):580-89.

88. Madani AS, Mirmortazavi A. Comparison of three treatment options for painful temporomandibular joint clicking. J Oral Sci. 2011;53(3):349-54.

89. Gil-Martínez A, Paris-Alemany A, López-de-Uralde-Villanueva I, La Touche R. Management of pain in patients with temporomandibular disorder (TMD): challenges and solutions. J Pain Res. 2018;11:571-87.

90. Zhang C, Wu JY, Deng DL, He BY, Tao Y, Niu YM, Deng MH. Efficacy of splint therapy for the management of temporomandibular disorders: a meta-analysis. Oncotarget. 2016;7(51):84043-53.

91. Raphael KG, Marbach JJ. Widespread pain and the effectiveness of oral splints in myofascial face pain. J Am Dent Assoc. 2001;132(3):305-16.

92. Nilner M, Ekberg E, Doepel M, Andersson J, Selovuo K, Le Bell Y. Short-term effectiveness of a prefabricated occlusal appliance in patients with myofascial pain. J Orofac Pain. 2008;22(3):209-18.

93. Oliveira SSI, Pannuti CM, Paranhos KS, Tanganeli JPC, Laganá DC, Sesma N, Duarte M, Frigerio MLMA, Cho SC. Effect of occlusal splint and therapeutic exercises on postural balance of patients with signs and symptoms of temporomandibular disorder. Clin Exp Dent Res. 2019;5(2):109-115.

94. Wahlund K, Larsson B. The course of pain intensity and frequency of adolescents treated because of temporoman- dibular disorders: A long-term follow-up. Clin Exp Dent Res. 2020;6(4):407-414.

95. Espí-López GV, Arnal-Gómez A, Cuerda Del Pino A, Benavent-Corai J, Serra-Añó P, Inglés M. Effect of Manual Therapy and Splint Therapy in People with Temporomandibular Disorders: A Preliminary Study. J Clin Med. 2020 28;9(8):2411.

96. Behr M, Stebner K, Kolbeck C, Faltermeier A, Driemel O, Handel G. Outcomes of temporomandibular joint disorder therapy: observations over 13 years. Acta Odontol Scand. 2007;65(5):249-53.

97. Daif ET. Correlation of splint therapy outcome with the electromyography of masticatory muscles in temporomandibular disorder with myofascial pain. Acta Odontol Scand. 2012;70(1):72-7.

98. Kurt H, Mumcu E, Sulun T, DiracoĞlu D, Unalan F, Aksoy C, Tuncer N. Comparison of Effectiveness of Stabilization Splint, Anterior Repositioning Splint and Behavioral Therapy in Treatment of Disc Displacement with Reduction. Turkish Journal of Physical Medicine \& Rehabilitation. 2011; 57(1)25-30:.

99. Majid IA, Mubeen FKA. Physiotherapy and Anterior Repositioning Splint in the Treatment of Disk Displacement with Reduction-A Randomized Controlled Trial. Journal of Evolution of Medical and Dental Sciences. 2020;9(52):3926-35.

100. Badel T, Ćimić S, Munitić M, Zadravec D, Kes VB, Šimunković SK. Clinical view of the temporomandibular joint disorder. Acta Clin Croat. 2014;53(4):462-70.

101. Wieckiewicz M, Boening K, Wiland P, Shiau YY, Paradowska-Stolarz A. Reported concepts for the treatment modalities and pain management of temporomandibular disorders. The journal of headache and pain. 2015;16(1):1-2.

102. Al Quran FA, Kamal MS. Anterior midline point stop device (AMPS) in the treatment of myogenous TMDs: comparison with the stabilization splint and control group. Oral Surgery, Oral Medicine, Oral Pathology, Oral Radiology, and Endodontology. 2006;101(6):741-7.

103. Fernandes G, Gonçalves DAG, Conti P. Musculoskeletal Disorders. Dent Clin North Am. 2018;62(4):553-64.

104.List T, Jensen RH. Temporomandibular disorders: Old ideas and new concepts. Cephalalgia. 2017;37(7):692-704.

105. Exposto FG, Renner N, Bendixen KH, Svensson P. Pain in the temple? Headache, muscle pain or both: A retrospective analysis. Cephalalgia. 2021;41(14):1486-91. 
106. Hugger S, Schindler HJ, Kordass B, Hugger A. Surface EMG of the masticatory muscles (Part 3): Impact of changes to the dynamic occlusion. Int $\mathrm{J}$ Comput Dent. 2013;16(2):119-23.

107. Lavigne G, Kim JS, Valiquette C, Lund JP. Evidence that periodontal pressoreceptors provide positive feedback to jaw closing muscles during mastication. J Neurophysiol. 1987;58(2):342-58.

108. Komuro A, Morimoto T, Iwata K, Inoue T, Masuda Y, Kato T, Hidaka O. Putative feed-forward control of jaw-closing muscle activity during rhythmic jaw movements in the anesthetized rabbit. J Neurophysiol. 2001;86(6):2834-44.

109. Helmy ES. Light microscopic and ultrastructural study of thinned discal areas in patients with temporomandibular joint internal derangement. Egypt Dent J. 1993;39(1):325-36.

110. Goodacre CJ, Roberts WE, Goldstein G, Wiens JP. Does the Stomatognathic System Adapt to Changes in Occlusion? Best Evidence Consensus Statement. Journal of Prosthodontics. 2021;30(S1):5-11.

111. Seligman DA, Pullinger AG. The role of functional occlusal relationships in temporomandibular disorders: a review. J Craniomandib Disord. 1991;5(4):265-79.

112. Verdonck A, Takada K, Kitai N, Kuriama R, Yasuda Y, Carels C, Sakuda M. The prevalence of cardinal TMJ dysfunction symptoms and its relationship to occlusal factors in Japanese female adolescents. J Oral Rehabil. 1994;21(6):687-97.

113. Tallents RH, Katzberg RW, Macher DJ, Roberts CA. Use of protrusive splint therapy in anterior disk displacement of the temporomandibular joint: a 1- to 3-year follow-up. J Prosthet Dent. 1990;63(3):336-41.

114. Conti PC, de Alencar EN, da Mota Corrêa AS, Lauris JR, Porporatti AL, Costa YM. Behavioural changes and occlusal splints are effective in the management of masticatory myofascial pain: a short-term evaluation. J Oral Rehabil. 2012;39(10):754-60.

115. Shousha TM, Soliman ES, Behiry MA. The effect of a short term conservative physiotherapy versus occlusive splinting on pain and range of motion in cases of myogenic temporomandibular joint dysfunction: a randomized controlled trial. J Phys Ther Sci. 2018;30(9):1156-60.

116. Linton SJ, Götestam GK. A clinical comparison of two pain scales: correlation, remembering chronic pain, and a measure of compliance. Pain. 1983;17(1):57-65.
117. Sousa BM, López-Valverde N, López-Valverde A, Caramelo F, Fraile JF, Payo JH, Rodrigues MJ. Different Treatments in Patients with Temporomandibular Joint Disorders: A Comparative Randomized Study. Medicina (Kaunas). 2020 5;56(3):113.

118. Di Paolo C, Falisi G, Panti F, Di Giacomo P, Rampello A. "RA. DI. CA." Splint for the Management of the Mandibular Functional Limitation: A Retrospective Study on Patients with Anterior Disc Displacement without Reduction. International Journal of Environmental Research and Public Health. 2020;17(23):9057.

119. Dao TTT, Lavigne GJ, Charbonneau A, Feine JS, Lund JP. The efficacy of oral splints in the treatment of myofascial pain of the jaw muscles: a controlled clinical trial. Pain. 1994;56(1):85-94.

120. Riley P, Glenny AM, Worthington HV, Jacobsen E, Robertson C, Durham J, Davies S, Petersen H, Boyers D. Oral splints for patients with temporomandibular disorders or bruxism: a systematic review and economic evaluation. Health Technol Assess. 2020;24(7):1-224.

121. Maloney GE, Mehta N, Forgione AG, Zawawi KH, AlBadawi EA, Driscoll SE. Effect of a passive jaw motion device on pain and range of motion in TMD patients not responding to flat plane intraoral appliances. Cranio. 2002;20(1):55-66.

122. Kümbüloğlu O, Saracoglu A, Bingöl P, Hatipoğlu A, Ozcan M. Clinical study on the comparison of masticatory efficiency and jaw movement before and after temporomandibular disorder treatment. Cranio. 2013;31(3):190-201.

123. de Felício CM, de Oliveira MM, da Silva MA. Effects of orofacial myofunctional therapy on temporomandibular disorders. Cranio. 2010;28(4):249-59.

124. Polso HL, Näpänkangas R, Raustia AM. Treatment outcome in patients with TMD--a survey of 123 patients referred to specialist care. Cranio. 2010;28(3):156-65.

125. Magnusson T, Syrén M. Therapeutic jaw exercises and interocclusal appliance therapy. A comparison between two common treatments of temporomandibular disorders. Swed Dent J. 1999;23(1):27-37.

126. Ekberg EC, Vallon D, Nilner M. Occlusal appliance therapy in patients with temporomandibular disorders. A double-blind controlled study in a short-term perspective. Acta Odontol Scand. 1998;56(2):122-8.

127. Conti PC, Corrêa AS, Lauris JR, Stuginski-Barbosa J. Management of painful temporomandibular joint click- 
ing with different intraoral devices and counseling: a controlled study. J Appl Oral Sci. 2015;23(5):529-35.

128. Conti PC, dos Santos CN, Kogawa EM, de Castro Ferreira Conti AC, de Araujo Cdos R. The treatment of painful temporomandibular joint clicking with oral splints: a randomized clinical trial. J Am Dent Assoc. 2006;137(8):1108-14.

129. Minervini G, Nucci L, Lanza A, Femiano F, Contaldo M, Grassia V. Temporomandibular disc displacement with reduction treated with anterior repositioning splint: a 2-year clinical and magnetic resonance imaging (MRI) follow-up. Journal of biological regulators and homeostatic agents. 2020;34(1):151-60.

130. Chen HM, Liu MQ, Yap AU, Fu KY. Physiological effects of anterior repositioning splint on temporomandibular joint disc displacement: a quantitative analysis. J Oral Rehabil. 2017;44(9):664-72.

131. Guo YN, Cui SJ, Zhou YH, Wang XD. An Overview of Anterior Repositioning Splint Therapy for Disc Displacement-related Temporomandibular Disorders. Curr Med Sci. 2021;41(3):626-34.

132. Williamson EH, Navarro EZ, Zwemer JD. A comparison of electromyographic activity between anterior repositioning splint therapy and a centric relation splint. Cranio. 1993;11(3):178-83.

133. Kurita H, Kurashina K, Baba H, Ohtsuka A, Kotani A, Kopp S. Evaluation of disk capture with a splint repositioning appliance: clinical and critical assessment with MR imaging. Oral Surg Oral Med Oral Pathol Oral Radiol Endod. 1998;85:377-80.

134. Kurita H, Kurashina K, Ohtsuka A, Kotani A. Change of position of the temporomandibular joint disk with insertion of a disk-repositioning appliance. Oral Surg Oral Med Oral Pathol Oral Radiol Endod. 1998;85(2):142-5.
135. Eberhard D, Bantleon HP, Steger W. The efficacy of anterior repositioning splint therapy studied by magnetic resonance imaging. Eur J Orthod. 2002;24(4):343-52.

136. Summer JD, Westesson PL. Mandibular repositioning can be effective in treatment of reducing TMJ disk displacement. A long-term clinical and MR imaging follow-up. Cranio. 1997;15(2):107-20.

137. Seo BY, Huh KH, An JS, Chang MS, Ahn SJ. Relationship of computed tomography-verified degenerative condylar morphology with temporomandibular joint disk displacement and sex. Oral Surg Oral Med Oral Pathol Oral Radiol. 2021;132(1):93-103.

138. Seo BY, An JS, Chang MS, Huh KH, Ahn SJ. Changes in condylar dimensions in temporomandibular joints with disk displacement. Oral Surg Oral Med Oral Pathol Oral Radiol. 2020;129(1):72-79.

139. Park JW, Song HH, Roh HS, Kim YK, Lee JY. Correlation between clinical diagnosis based on RDC/TMD and MRI findings of TMJ internal derangement. Int J Oral Maxillofac Surg. 2012;41(1):103-8.

140.Kurita H, Uehara S, Yokochi M, Nakatsuka A, Kobayashi $\mathrm{H}$, Kurashina K. A long-term follow-up study of radiographically evident degenerative changes in the temporomandibular joint with different conditions of disk displacement. Int J Oral Maxillofac Surg. 2006;35(1):49-54.

141.Katzberg RW, Keith DA, Ten Eick WR, Guralnick WC. Internal derangements of the temporomandibular joint: an assessment of condylar position in centric occlusion. $\mathrm{J}$ Prosthet Dent. 1983;49(2):250-4.

142. Ronquillo HI, Guay J, Tallents RH, Katzberg RW, Murphy W. Tomographic analysis of mandibular condyle position as compared to arthrographic findings of the temporomandibular joint. J Craniomandib Disord. 1988; 2(2):59-64. 